\title{
Dendroclimatic Estimates of a Drought Index for \\ Northern Virginia
}

GEOLOGICAL SURVEY WATER-SUPPLY PAPER 2080

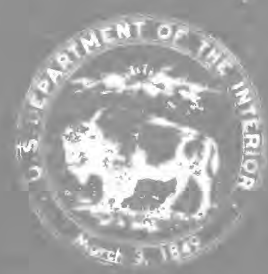




\section{Dendroclimatic Estimates of a Drought Index for Northern Virginia}

By LARRY J. PUCKETT

GEOLOGICAL SURVEY WATER-SUPPLY PAPER 2080

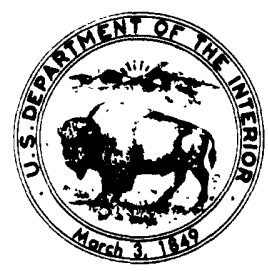


UNITED STATES DEPARTMENT OF THE INTERIOR

JAMES G. WATT, Secretary

GEOLOGICAL SURVEY

Dallas L. Peck, Director

First printing 1981

Second printing 1982

For sale by the Superintendent of Documents, U.S. Government Printing Office Washington, D.C. 20402 


\section{CONTENTS}

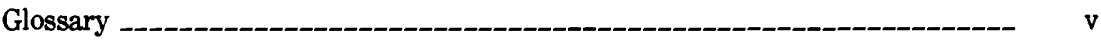

Abstract _-_-_-_-_-_-_-_-_-_-_-_-_-_-_-_-_-_-_-_-_-_-_-_-_-_-_-_-_-_-- 1

Introduction and objectives -_-_-_- 1

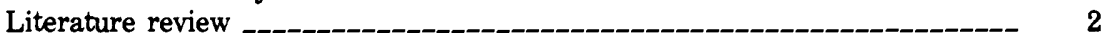

General approach -

Species selection _-_-_-_-_-_-_-_-_-_-_-_-_-_-_-_-_-_-_-_-_-_-_-_-_-_-- 6

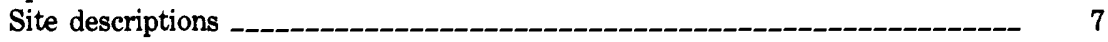

Burling Tract _-_-_-_-_-_-_-_-_-_-_-_-_-_-_-_-_-_-_-_-_-_-_-_-_-_-- 8

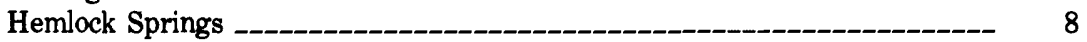

Ramseys Draft _-_-_-_-_-_-_-_-_-_-_-_-_-_-_-_-_-_-_-_-_-_-_-_ 8

Climate and weather data

Construction of the tree-ring chronology -_-_-_-_-_-_-_-_-_-_-_-_ 11

Sample collection and preparation _-_-_-_-_-_-_-_-_-_-_-_-_-_-_-_-- 11

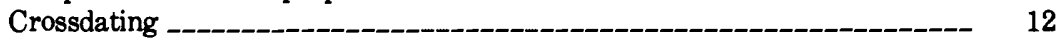

Measurement and computer processing -_-_-_-_-_-_-_-_-_-_-_-_-_-- 13

Chronology statistics _-_-_-_-_-_-_-_-_-_-_-_-_-_-_-_-_-_-_-_ 13

Formation of a model of the growth-climate relationship _-___-_-_-_____-_- 16

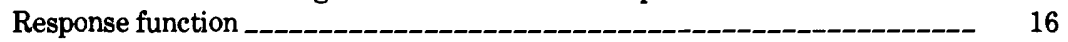

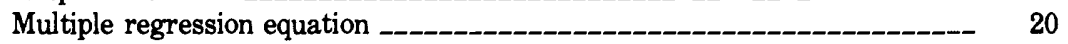

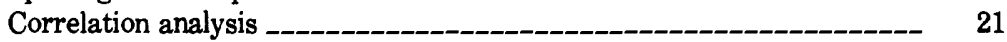

Calibration of the tree-growth record with the climatic record

Methods of calibration -__-_-_ 23

Discussion of regression results _-_-_-_-_-_ 25

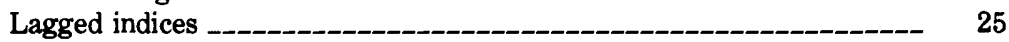

Eigenvector amplitudes _._-_-_-_ 27

Reconstruction results _-_-_-_-_-_ 29

Apparent shift in reconstruction - 29

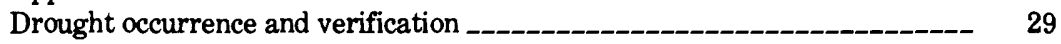

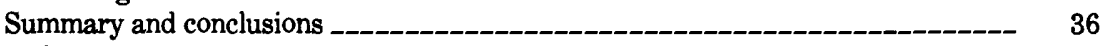

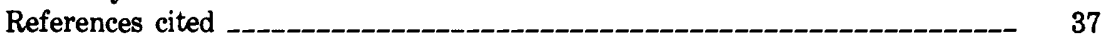

\section{ILLUSTRATIONS}

FIGURE 1. Maps showing location of the three hemlock sampling sites, Burling

Tract, Hemlock Springs, Ramseys Draft, Va _-______-__-_-_-_

2. Plots showing response-function results - Flow chart for procedures used in making statistical estimates of the July Palmer drought-severity index (PDSI) 
Figures 4-7. Plots showing:

4, 5. Reconstructed Northern Virginia and Central Mountain climatic-division and Virginia Average July PDSI for the period 1746-1975:

4. And the actual July PDSI for the period $1931-75$, using lagged indices of growth as predictors

5. Using indices of growth and factor scores as predictors

6. The actual Northern Virginia climatic-division July PDSI, compared with the actual Washington, D.C., July PDSI and the reconstructed Northern Virginia July PDSI, for the period 1931-75

7. The estimated July PDSI for the Northern Virginia and Central Mountain climatic divisions, with data for the Washington, D.C., July PDSI for the period 1817-1975 and for the New York July PDSI for the period 1746-1972 used for verification

\section{TABLES}

TABLE 1. Classification of dry or wet conditions by the Palmer drought-severity index (PDSI)

2. Summary of chronology statistics, by site

3. Correlations between lagged growth indices for Burling Tract, Hemlock Springs, and Ramseys Draft and the July PDSI for the Northern Virginia and Central Mountain climatic divisions and the Virginia Average, 1931-1975

4. Maximum $R^{2}$ for each regression model, 1931-1975, with combination of chronologies used

5. Combinations of variables resulting from the calibration of tree rings with the divisional PDSI for the period, 1931-1975

6. Correlations between the computed PDSI for Washington, D.C., Northern Virginia and Central Mountain climatic divisions, and the Virginia Average, 1931-1975

7. Proportion of dry, near-normal, and wet years that have occurred in selected time periods, based on an equal probability of occurrence between the three classes 


\section{GLOSSARY}

Autocorrelation. A statistical measure of the correlation between consecutive values of a time series; also referred to as serial correlation.

Calibration. The process of computing (calculating) a mathematical relationship that can be used to estimate a predictand variable from one or more predictor variables.

Chronology. In dendrochronology the mean of the standardized indices of growth of all tree samples over time at a particular site.

Complacent. The lack of ring-width variability due to tree growth under conditions not limited by climatic variations.

Crossdating. The procedure of establishing the precise year of tree ring formation by matching patterns of ring-width variation among the samples of a collection of incremental cores.

Dendroclimatology. The science of estimating prior climatic conditions on the basis of growth response of trees to variations in climate.

Eigenvalues. A set of coefficients, each of which is proportional to the amount of variance reduced by the eigenvector to which it corresponds.

Eigenvectors. An array of transformed variables that are orthogonal and represent the patterns of variance of the untransformed data; also referred to as principal components.

Eigenvector amplitudes. The elements of a matrix derived by multiplying the eigenvectors by the normalized climatic data from which they were obtained; also referred to as factor scores.

Factor scores. See eigenvector amplitudes.

High-frequency variance. Variations in a time series that occur with durations of 8 years or less; usually used in reference to year-to-year variation.

Low-frequency variance. Variations in a time series that occur with durations greater than 8 years.

Mean sensitivity. The average relative difference in successive ring widths of an increment core.

Orthogonal. Independent, uncorrelated.

Palmer drought severity index. A measure of meteorological drought based on temperature, precipitation, and local factors affecting water availability in the soil.

Principal component. See eigenvector.

Reconstruction. A statistical estimate of past climatic conditions calculated from ringwidth chronologies.

Response function. A statistical procedure utilizing stepwise multiple regression to derive weights that describe how tree growth responds to climatic variables.

Ring-width indices. Standardized values of ring-width measurements having a mean of 1.0.

Serial correlation. See autocorrelation.

Standardization. The process of transforming ring widths to ring-width indices while removing the effects of aging. See ring-width indices. 


\title{
DENDROCLIMATIC ESTIMATES OF A DROUGHT INDEX FOR NORTHERN VIRGINIA
}

\author{
By LARRY J. PUCKeTt
}

\section{ABSTRACT}

A 230-year record of the Palmer drought-severity index (PDSI) was estimated for northern Virginia from variations in widths of tree rings. Increment cores were extracted from eastern hemlock, Tsuga canadensis (L.) Carr., at three locations in northern Virginia. Measurements of annual growth increments were made and converted to standardized indices of growth.

A response function was derived for hemlock to determine the growth-climate relationship. Growth was positively correlated with precipitation and negatively correlated with temperature during the May-July growing season. Combined standardized indices of growth were calibrated with the July PDSI. Growth accounted for 20-30 percent of the PDSI variance. Further regressions using factor scores of combined tree growth indices resulted in a small but significant improvement. Greatest improvement was made by using factor scores of growth indices of individual trees, thereby accounting for 64 percent of the July PDSI variance in the regression.

Comparison of the results with a 241-year reconstruction from New York showed good agreement between low-frequency climatic trends. Analysis of the estimated Central Mountain climatic division of Virginia PDSI record indicated that, relative to the longterm record (1746-1975), dry years have occurred in disproportionally larger numbers during the last half of the 19th century and the mid-20th century. This trend appears reversed for the last half of the 18th century and the first half of the 19th century. Although these results are considered first-generation products, they are encouraging, suggesting that once additional tree-ring chronologies are constructed and techniques are refined, it will be possible to obtain more accurate estimates of prior climatic conditions in the mid-Atlantic region.

\section{INTRODUCTION AND OBJECTIVES}

Extreme climatic variation, drought in particular, has a serious effect on man and his society. Historically, crop failures and famine have frequently followed or accompanied widespread or long term droughts. Today, with our capacity to store great volumes of water we might expect droughts to have little effect. However, as our population continues to grow, the water supplies of many communities are all too often unable to meet the demand placed upon them. This becomes critical during periods of moderate to extreme drought. To avoid crises, advance planning and resource development is a necessity.

The object is, through analysis of long climatic records, to predict the probability of droughts and thus be able to plan for them. One of the main stumbling blocks is the lack of continuous, long-term climatic 
records. In areas where a climatic record of sufficient length is not available, determination of the probability of drought may be aided by the development of a substitute or proxy record.

In both North Carolina and New York, recent research based on the relationship of tree growth to climate has demonstrated the feasibility of dendroclimatic reconstructions in humid regions. Using multivariate techniques developed for the semiarid Southwest, proxy records of precipitation and drought severity have been reconstructed (Cleaveland, 1975; Cook and Jacoby, 1977). It is the objective of this study to use similar dendroclimatic techniques to reconstruct a proxy record of drought for the Northern Virgina and the Central Mountain climatic divisions of Virginia.

\section{LITERATURE REVIEW}

Early studies in dendrochronology and dendroclimatology began in the late 1890's with A. E. Douglas' work at Lowell Astronomical Observatory in Flagstaff, Ariz. (Fritts, 1976). Douglas was primarily interested in sunspot cycles and their effect on the Earth's climate. Quite by accident, he noticed that tree-ring widths often displayed patterns that correlated fairly well with precipitation. Although he was not able to detect any further relation to sunspot activity, his pioneering work in the field (along with that of several of his students) attracted the interest of eastern ecologists.

Work on dendroclimatology in the East began during the early 1930 's, owing possibly to an extensive drought at the time. Eastern hemlock, Tsuga canadensis (L.) Carr., was the species most studied during this early period, although with varying degrees of success.

Stickel (1933) conducted mortality studies of hemlock near New Haven, Conn., in relation to the drought of 1929-30. Although of an ecological nature, these studies were basic to understanding the drought sensitivity of hemlock. His results indicated a definite relationship between soil moisture and stand survival. Stands that were on "trap rock ridges" (that is, over impervious bedrock) showed greatest mortality; those in areas of ground-water seepage had a higher survival rate. The importance of this lies with the suggestion that the most climatically sensitive trees would be found on trap rock ridges owing to this soil-moisture limitation.

Hough and Forbes (Hough, 1936; Hough and Forbes, 1943) conducted an intensive study of the virgin hemlock stand on East Tionesta Creek in northwestern Pennsylvania. This, too, was an ecological study that produced only qualitative dendroclimatic information. From ring count studies of stumps, it was determined that the decade 1545-1554 A.D. was extremely favorable for hemlock reproduction. This was noted also to be the case to a lesser degree for the entire period 
1514-1575 A.D. A drought and fire in 1644 and a tornado in 1811, which resulted in extensive wind throw, were also determined to have occurred.

Lyon (1935) made the first studies in eastern dendrochronology using techniques similar to those in use today. A chronology of average ring widths was constructed using measurements of three radii of two hemlock cross sections. The radii cross dated with each other, as well as with a Vermont hemlock chronology prepared by Douglas (1919). Total April through August precipitation was then compared with the chronology to determine a growth-climate relationship. Using this technique, Lyon was able to identify distinct drought years (1640, 1681-82, 1749, 1876), as well as longer periods of drought in the seventeenth, eighteenth, nineteenth, and twentieth centuries.

In a later study Lyon (1936) measured growth increments of fortyseven trees from six sites (two in Vermont and four in New Hampshire). Again cross-dating between the sites was consistent. This he surmised was "due to dominance of the factor of physiological dryness". Lyon compared May to August total precipitation with ring width. Through qualitative analysis he found twice as many years of physiological drought between 1600 and 1934 as wet years. Because available weather information was not a good indicator of potential growing conditions, Lyon proposed that hemlock growth, as he analyzed it, offered a better and longer record.

Schumacher and Day (1939) used a polynomial curve to standardize ring width measurements from a hemlock chronology constructed by Lyon. Regression analysis was used to derive a relationship between growth and orthogonal polynomial coefficients of prior June to current August precipitation. According to Schumacher and Day, the tolerance of hemlock to competition contributed to the lack of any significant relationship being established.

Avery and others (1940) conducted a study of hemlock growing on a ridge versus those next to a stream. Pearson correlation coefficients were calculated for annual increment measurements at the two sites. This produced evidence of considerable correlation between the two collections. However, correlation between tree growth and climatic data was considerably less encouraging.

Meyer (1941) fit growth trend curves to the measurements of annual growth increments of 16 trees from two sites in northern Pennsylvania. He then performed an analysis of variance on the last 50 measurements for the collections. Although only 17.5 percent and 19.5 percent of the variance in growth were in common at each of the two sites, Meyer was surprised to find no significant relationship between climate and growth. This was in spite of the fact, as he recognized, that rainfall was not a limiting factor in northern Pennsylvania. 
Lyon (1941) looked at cross-correlation between hemlock, red spruce, and white pine from 13 separate sites in New Hampshire. His best correlations were intraspecific, among hemlock sites $(0.523)$, white pine sites $(0.371)$, and red spruce sites $(0.320)$. Interspecific correlations at a given site were not as high. This was highly significant in that it indicated that trees of the same species from separate sites responded in a similar manner to climatic factors.

Using hemlock from four sites and white pine from seven other sites in the Boston, Mass., area, Lyon (1943) measured annual ring widths. The widths at each site were averaged for each year and used as indices of growth. Lyon's comparison of growth with local weather data indicated the "importance of rainfall during the prior growing season." He also noted a lag in growth response to the climate of the previous year, which he attributed to soil water supplies. He pointed out that cross dating among trees in the Boston area and ones in New Hampshire was not possible owing to local drought conditions, which occurred in addition to more widespread droughts.

Fritts, beginning in 1958 and with various coworkers through 1976, developed techniques that have revolutionized dendroclimatology. In the early 1960's Fritts (1962) introduced the use of multiple regression techniques to dendroclimatology. This was followed by the development of computer programs for standardizing tree-ring measurements (Fritts, 1963; Fritts and others, 1969), and, with Julian (Julian and Fritts, 1968), he introduced new methods of statistical analysis.

An important development in dendroclimatology, however, was the introduction of a multivariate response-function technique (Fritts and others, 1970), making it possible to use multivariate analysis of orthogonal variables to establish the relationship of tree growth to climatic variables during the current and prior growing season (commonly 15 or 16 months). Modeling the growth-climate relationship was made considerably more accurate with the use of this technique.

The first attempt at estimation of climatic records in the East using these new techniques was undertaken by Cleaveland (1975) in North Carolina, using incremental cores of shortleaf pine (Pinus echinata Mill.) to construct a 291-year chronology. His analysis employed treering measurements, X-ray densitometry, and growth-response analysis. A 291-year reconstruction of June, July, and August totalprecipitation records using latewood growth measurements was produced.

The first attempt at estimating the Palmer drought-severity index (PDSI) (page 9) was made by Stockton and others (1978). Using principal component analysis and canonical analysis, a 275-year reconstruction of the July PDSI for forty regions in western North America was made. Power spectrum analysis was used to determine the periodicity of drought for the reconstruction. 
Cook (1976) studied four tree-ring chronologies that he constructed from collections in the Hudson Valley region of New York. The trees were growing on high-altitude ridges and talus slopes that resembled sites in the semiarid Southwest. Analyses of the cross correlation among the chronologies and of the correlation with climate was done in addition to growth response analysis. The results indicated an excellent potential for the reconstruction of climatic variables in the Northeast.

By use of the chronologies constructed by Cook (1976) for the Hudson Valley of New York, Cook and Jacoby (1977) made a 241-year reconstruction of the July PDSI. They employed multiple regression of principal components of growth indices with PDSI to derive the reconstruction. Verification was achieved with May to July total rainfall data from 1840-1930.

Rapid development of techniques in dendroclimatology in the past decade has made it possible to estimate records of climatic variables even in humid regions. The challenge for the immediate future is to adapt and use these techniques in the East, where competition and environmental factors complicate the growth-climate relationship.

\section{GENERAL APPROACH}

The objective of this study is to determine estimates of prior drought severity for the Northern Virginia and Central Mountain climatic divisions of Virginia. This is accomplished by relating indices of tree growth to an index of drought severity using stepwise multiple regression analysis. Three basic steps are involved in estimating drought: the devising and development of a tree growth-climate model, calibration with multiple regression analysis, and computation and verification. The procedure first involves development of a model describing the tree growth-climate relationship by regressing transformed monthly temperature and precipitation variables against indices of tree growth. These climatic variables are transformed by means of principal component analysis into truly independent variables, thereby fulfilling one of the constraints of multiple regression analysis. Regression weights are computed, which are then used to determine the month during which temperature and precipitation and therefore drought severity are most limiting to tree growth.

Once the month during which drought severity is most limiting to tree growth has been determined, indices of growth are regressed against the drought-severity index over a common period of time. Indices of growth can also be transformed by the principal components procedure before being used in the regression procedure. The regression coefficients computed in this procedure are then used along with the measure of tree growth to estimate prior values of drought severity. As a means of verifying the drought estimates, they are 
compared with actual climatic data and with other previously verified estimates of drought.

Finally, the drought-severity estimates are divided into several time periods and analyzed for percent of dry, normal, and wet years. Comparison of the results are made so as to detect any change in the frequency of drought occurrence with time.

\section{SPECIES SELECTION}

Eastern Hemlock, Tsuga canadensis (L.) Carr., was chosen for this study for its record of longevity of as much as 500 years (Hough and Forbes, 1943) and, more importantly, for its typical shallow root system and site locations in Virginia. It was felt that these last two conditions would contribute to the climatic sensitivity of the trees and, therefore, the quality of the chronologies.

Hemlock is most widely distributed in the Northeast but extends southward to Alabama and Georgia. In Virginia it is most commonly found on north-facing slopes of steep, moist gorges and ravines in the mountains. In the Piedmont it is uncommon, and in the Coastal Plain it is practically nonexistent. At all the sites visited during this study, the soil was rocky and apparently well drained and contained a shallow humus layer. Also, areas of bedrock were exposed at several sites. This, along with the shallow-rooted growth habit of hemlock, would seem to contribute to the reported drought sensitivity of the species (Hough, 1965).

Stickel (1933), Hough (1936), and Lyon (1936) all noted the considerable damage to hemlock during the extensive drought of the early 1930 's. The greatest mortality was to ancient and less vigorous trees. In southern locations this susceptibility to drought coupled with higher average temperatures limits the species to wetter, more protected locations. In addition, the effects of drought are probably moderated by the microclimate of a mature stand. Once a continuous canopy is formed, sunlight reaching the forest floor is considerably reduced (Hough, 1965). The resulting reduction in evaporation and temperature (Segars and others, 1951; Oosting and Hess, 1956) probably conserves soil moisture, thereby allowing hemlock to survive on drier sites than would otherwise be possible during droughts.

Hemlock in Virginia seems to be restricted to sites of normally abundant soil moisture and might therefore be expected to show only weak responses to minor fluctuations in water. However, owing at least in part to shallow root systems, the trees may be extra sensitive to extreme drought. 


\section{SITE DESCRIPTIONS}

In an attempt to collect samples from as wide a geographical range as possible, all known hemlock sites in the Virginia Coastal Plain, Piedmont, and several sites in the mountains were visited. Although samples were collected at all sites, only three yielded samples of sufficient age and climatic sensitivity for use in this study (see Chronology Statistics, p. 15). Although all were similar in respect to the hemlock microenvironment, they collectively represented a wide geographical range across northern Virginia (fig. 1), and each was macroenvironmentally different.

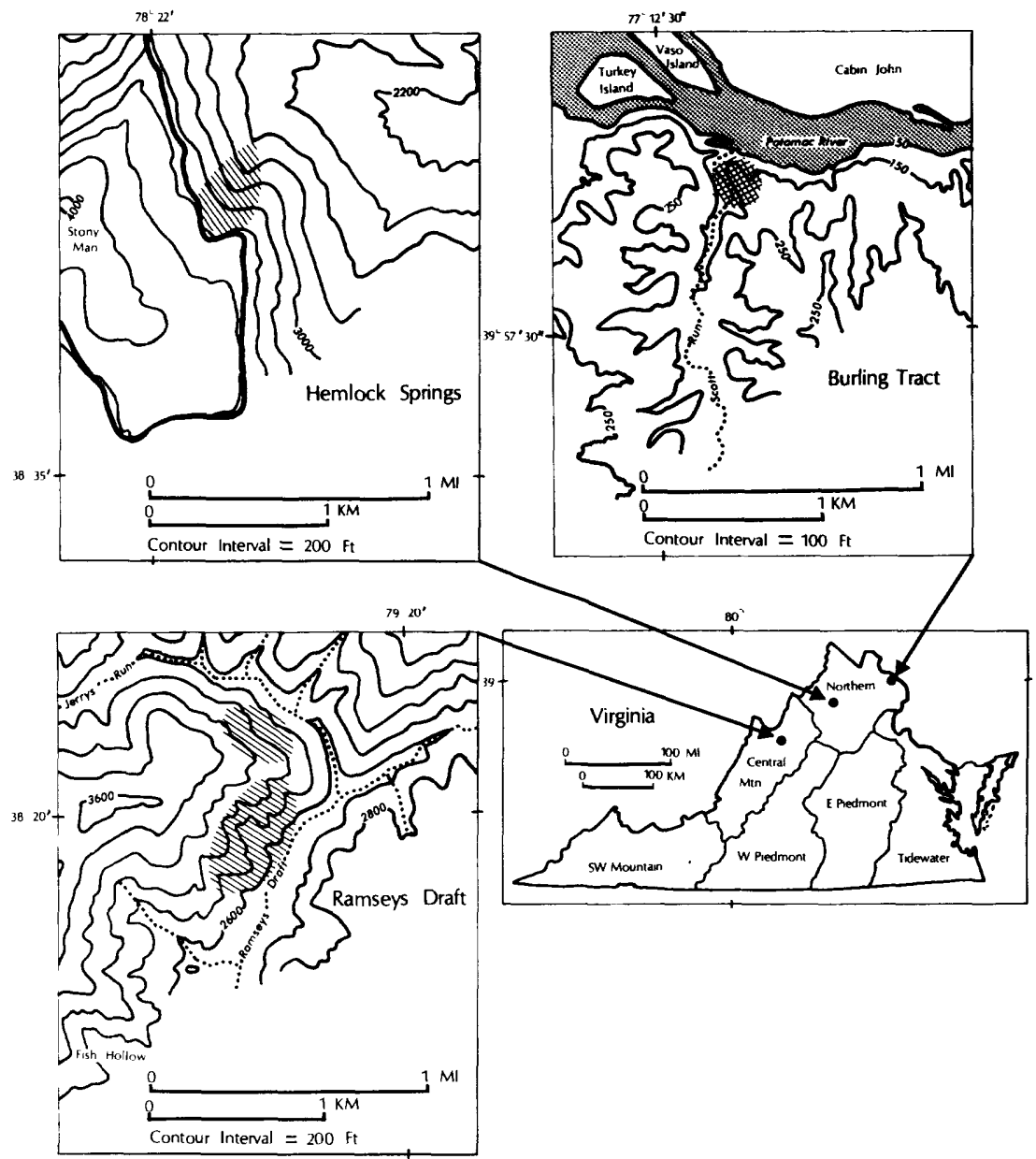

FIGURE 1.-Maps showing location of the three hemlock sampling sites, Burling Tract, Hemlock Springs, Ramseys Draft, Va. The Virginia map shows the boundaries of the six climatic divisions. 


\section{BURLING TRACT}

The Burling Tract (fig. 1) is located in Fairfax County on Scott Run, adjacent to the Potomac River. Except in extreme drought years, growth of trees at this site is probably not limited by soil water. Soil on the slope consists only of a very thin humus layer over a bedrock of sandstone and highly metamorphosed schist (Fisher, 1963). In many places trees are growing directly on bedrock with their roots extending into cracks. On the less steep upper slope, litter and humus is much thicker and the growth rings of trees are larger, possibly indicating greater soil moisture.

The maximum age determined from tree-ring dating was 236 years. All the trees became established prior to 1860 , and 5 of the 13 predate 1800 . This indicates relative freedom from disturbance for at least the past 200 years. Presently, seedlings and saplings are primarily limited to the edges of the stand, with only a few small seedlings scattered under mature trees.

\section{HEMLOCK SPRINGS}

At Hemlock Springs (fig. 1) a continuous hemlock stand begins at Skyline Drive in Shenandoah National Park at an altitude of $3,400 \mathrm{ft}$ $(1,050 \mathrm{~m}$ (meters)) and covers a steep northeast slope down to an altitude of about $2,400 \mathrm{ft}(730 \mathrm{~m})$. There is an intermittent stream in the area and, as the name of the site implies, evidence of groundwater seepage. The humus layer is thin and broken throughout by boulders and rocks, which provide excellent drainage in this surficial deposit (Reed, 1969).

As at Burling Tract, maximum age determined was 236 years, and the distribution of ages of individual trees was similar to that in Burling Tract. Few seedlings and saplings were noted, indicating that disturbance in the area has been minimal over a considerable time. High altitude coupled with reliable soil moisture probably provide excellent growing conditions for the trees. The limited reproduction is assumed to indicate mature stands and is the result of insufficient light penetration through the continuous hemlock canopy.

\section{RAMSEYS DRAFT}

The Ramseys Draft Wilderness Area, Augusta County, Va., (fig. 1) is interesting both geologically and botanically. Ramseys Draft, the major stream, flows northeast to southwest through the McClung Syncline. The dip of the rock strata is toward the stream valley from the ridges on the west and east (Lesure and Geraci, 1977). The porous bedrock, along with the dip of the strata, probably contributes to the extensive groundwater seepage and permanent springs. Also, owing to 
an altitude of $2,400-3,400 \mathrm{ft}$ ( $730-1,050 \mathrm{~m})$, average temperatures are low. Consequently, the vegetation of the area resembles that of the northeastern deciduous hardwoods, and hemlock is widespread within the area. Humus is moderate to thick even on steep slopes. Reproduction is excellent on recently disturbed flat areas adjacent to the streams. The maximum age of hemlock was 318 years and is probably due to excellent growing conditions and lack of extensive disturbances in the area.

\section{CLIMATE AND WEATHER DATA}

Three main terrestrial factors determine the climate of Virginia -- topography, latitude, and the Atlantic Ocean, according to Crockett (1971). The State is in or near the path of both winter storms coming from the west and moist, tropical air masses coming in from the Gulf of Mexico and southwest Atlantic during the summer and early fall. The influence of oceanic weather patterns is limited mainly to coastal regions because of prevailing westerlies. This effectively creates a climatic gradient from west to east.

The influence of topography is twofold. Average temperature decreases as elevation increases. More importantly, however, the mountains deflect the prevailing winds and storm patterns. This influence is lessened during the winter months when polar air masses move in from the north.

Precipitation during the winter is commonly due to low-pressure systems entering the State from the west and north. Precipitation is more evenly distributed in winter than in summer, when the maximum occurs as local showers and thunderstorms.

According to Crockett (1971), droughts damaging to plants occur in at least some section of Virginia on an average of 1 year in 3 . The potential for severe drought is heightened from May to August because losses by evapotranspiration almost equal average precipitation. Any prolonged deviation in precipitation below the norm can cause a severe water deficit (Crockett, 1971).

As a means of measuring the severity of drought, Palmer (1965) devised a meteorological-drought index, which has since been referred to as the Palmer drought-severity index (PDSI). The Palmer index for month $i$ is determined through the following relation:

$$
\operatorname{PDSI}_{i}=0.897 \mathrm{PDSI}_{i-1}+1 / 3 Z_{i} \text {. }
$$

Carryover of soil moisture from one month to the next is reflected in this relation along with adjustments to soil moisture through the term $Z_{i}$,

$$
Z_{i}=k_{j}\left(P_{i}-\left(\alpha_{j} E_{i}+\beta_{j} G_{i}+\gamma_{j} R_{i}-\delta_{j} L_{i}\right)\right),
$$


in which the subscript $j$ represents one of the calendar months and $i$ is a particular month in a series of months. $P_{1}$ is precipitation for month $i$, and the remaining variables within the parentheses are determined using a moisture accounting scheme. Respectively, $E_{i}, G_{i}, R_{i}$, and $L_{i}$ are potential evapotranspiration, soil moisture recharge, surface runoff (excess precipitation), and soil moisture loss for month $i$. The coefficients $\alpha_{j}, \beta_{j}, \gamma_{j}$, and $\delta_{j}$ are the ratios for long term averages of actual to potential magnitudes for $E, G, R$, and $L$ based on a standard 30-year climatic period. Potential evapotranspiration, $E_{h}(h=i$ or $j)$, is determined using the Thornthwaite method (Thornthwaite, 1948). $G_{n}$, the potential soil moisture recharge, is the moisture required to bring the soil to field capacity. $R_{h}$ is the potential surface runoff that would occur if $E_{k}=0$ and is equal to the field capacity of the soil less the potential recharge. Potential moisture loss from the soil, $L_{h}$, is equal to the potential evapotranspiration, $E_{k}$, plus the moisture required to return the soil to field capacity, $G_{n}$.

The constant $k_{j}$ accounts for variations in regional and seasonal climate, giving the PDSI a common base, therefore allowing temporal and spatial comparison of monthly values. $k$, is determined from the expression

$$
k_{j}=\frac{E_{j}+G_{j}}{P_{j}+L_{j}},
$$

where the subscript $j$ indicates average magnitude, for the standard 30-year climatic period, of the variables in month $j$.

The PDSI values range from less than -4 to greater than +4 (table 1 ), with -0.49 to +0.49 as the near normal range. The values exceed -4 and +4 only during extreme conditions. Because the moisture content of the soil for preceding months partially determines soil moisture for any given month, considerable serial correlation exists in the index values. Therefore, an index value for a particular month may indicate soil moisture conditions for several preceding and succeeding months.

TABLE 1.-Classification of dry or wet conditions by the Palmer drought-severity index (PDSI)

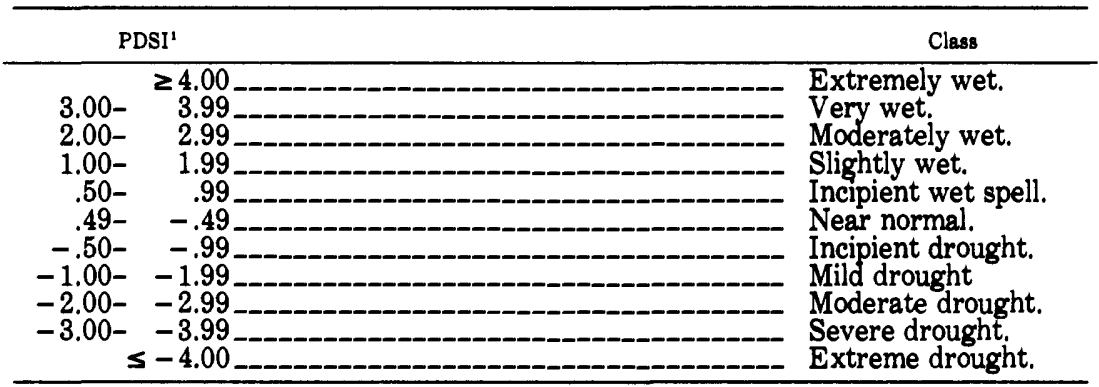

${ }^{1}$ Palmer (1965). 
July is a good month with which to work because, according to Phipps (1961), the major flush of growth of most eastern trees occurs before August. In addition, those climatic conditions that have influenced tree growth for the preceding 4 or 5 months also play a large part in determining the index value for July. The index, then, is a convenient climatic parameter to estimate from tree growth.

The PDSI values used in this study were obtained from the National Climatic Center, Asheville, N.C. Each State has been divided into climatic divisions, and the monthly drought indices for each are available for the period 1931 to the present. Monthly precipitation and temperature from all weather stations within the division are averaged to give mean monthly precipitation and monthly temperature values, which, along with certain constants, are used to compute the PDSI.

In addition to the computed PDSI values, a copy of the PDSI computer program was acquired from the National Climatic Center. The July PDSI was computed back to 1817 using monthly precipitation and temperature data from Washington, D.C. This was used in the verification of the reconstructed PDSI series. Further verification was achieved by using a 241-year reconstruction furnished by E. R. Cook of the Lamont-Doherty Geological Observatory, Palisades, N.Y. Although this reconstruction was for the Hudson Valley region (approximately 300 miles (480 kilometers) to the northeast) it was assumed that major climatic trends for the northeast would appear in both.

\section{CONSTRUCTION OF THE TREE-RING CHRONOLOGY}

\section{SAMPLE COLLECTION AND PREPARATION}

Owing to the problems associated with obtaining cross sections of trees, the majority of dendrochronology studies use incremental cores as wood samples. These are extracted from the trees with the use of standard increment borers of either 4.3 or $5.0-\mathrm{mm}$ diameter. The larger borers are more desirable for hemlock because cores of the smaller diameter are more likely to break or twist. Twisting of cores makes it difficult to obtain a surface with the tracheids and other cells perpendicular to the surface to be measured.

Cores were collected from at least two radii per tree (usually from opposite sides). The trees, all of which were growing on slopes, were not cored on the upslope or downslope sides. This was done to avoid eccentric growth due to the formation of reaction wood. Reaction wood in conifers is commonly called compression wood and is noted by considerably larger growth rings on the downslope side. Deciduous trees form tension wood with the differential growth on the upslope side (Cutter, 1971).

The extracted cores were placed in paper soda straws, which have proved to be excellent containers for storage since they are rigid, 
preventing breakage of the core, and do not retard the drying process. Hemlock cores were found to be too fragile to withstand this repeated handling. Therefore the cores were later permanently glued in grooved wooden blocks, with the tracheids vertical.

In order to distinguish tree-ring boundaries it is necessary to surface each core prior to crossdating and measurement. The goal of surfacing is to provide a smooth transverse surface on the wood resembling a clean blade cut. This, in turn, provides a sharp distinction of cell wall boundaries. The most practical means of surfacing dry cores is through sanding. Sanding and buffing were done with the sanding disk mounted in a drill press, which provided a greater range of speeds and control than could be achieved with either an electric hand drill or sander.

\section{CROSSDATING}

To insure absolute dating and to identify missing or false rings, it was necessary to crossdate the cores before measurement. Crossdating followed the procedure outlined by Stokes and Smiley (1968), as modified at the U.S. Geological Survey Tree-Ring Laboratory.

Crossdating is the process of matching identical patterns of ring widths between the cores of a collection. This insures that the assigned date for each ring is not off by 1 or more years because of missing or false rings. Missing rings can occur in response to limiting conditions during a growing season, but in the hemlock of this study they were not noted. False rings were easy to distinguish, consisting of a band of cells with thick walls that lack a sharp outer ring boundary.

Crossdating, although fairly simple, was done with utmost care and was the single most time-consuming process in chronology building. Dating started with the last ring formed and continued in reverse chronological order. As the cores were dated, notes were made regarding narrow, large or otherwise uncommon rings and distinctive patterns of narrow and large rings. Once several cores were dated in this manner, those patterns which occurred consistently were used as key crossdating years. As each of the remaining cores was dated, key years that had not been previously noted were added. The final set of crossdating key years included those found in a significantly large number of cores. As long as key years matched from one core to another, little chance of overlooking false or missing rings existed. However, if a date was off by 1 or more years, efforts were made to locate the missing or false ring and thus to date the core correctly. This was done by matching individual years within the period in question, until one ring that had no possible mate was singled out. Only through proper crossdating can the absolute dates of a chronology be established, and it is probably the most important step in chronology building. 


\section{MEASUREMENT AND COMPUTER PROCESSING}

A properly surfaced and dated core was placed on a mechanical moving stage and ring widths were measured in hundredths of millimeters. Each ring boundary was lined up with a cross-hair in a dissecting-microscope ocular, and as the core passed this point, the operator pushed a button that entered the ring-width value onto magnetic tape. Once an entire core was measured twice, it was ready for computer processing. Cores were measured twice to insure that operator error was not beyond an acceptable level, as determined by measurement error.

To transform the data into a usable form, the two measurements of each ring were averaged. A computer program, TRIM, was used to calculate and print ring widths (average of the two measurements), mean sensitivity, and measurement error for each core. Mean sensitivity (Fritts, 1976) is a measure of the average, absolute change in ring width from one year to the next and may be regarded as a measure of width variability from ring to ring. In general, the larger the mean sensitivity, the more responsive to climate the tree is likely to have been. Measurement error is a statistically derived measure of the deviations of the measurements from the calculated mean for each ring width. As long as the difference between the two measurements of a core was $\pm 0.05 \mathrm{~mm}$ or less, the mean was considered sufficiently accurate to accept; if it was greater than $\pm 0.05 \mathrm{~mm}$ the core was remeasured.

Finally the data were converted to standardized indices having a mean of 1.0, using a version of the INDXA program developed by Fritts (1963). This program fits either a straight line, negative exponential curve, or a polynomial curve to the ring width values of the tree, and then the ring widths are divided by the corresponding curve values to produce the indices. Standardized indices are much more desirable to work with because data for trees having consistently larger growth rings will not dominate when the entire collection is averaged together to form a chronology.

The analysis of variance, ANOVA, subroutine of INDXA, is used to compute between-tree variance, between-core variance, and variance common to the collection. The common variance is generally accepted as the response due to climate. In the East, we can expect climate to account for about 25 percent of the variance of a good chronology. Good western chronologies, on the other hand, may have 60 percent of the common variance based on climate (Fritts, 1976).

\section{CHRONOLOGY STATISTICS}

Several basic statistics are commonly used to describe a chronology of either widths or indices. Standard deviation $\left(s_{x}\right)$, the square root of 
the variance, is a measure of dispersion of data about their mean (Fritts, 1976). Because $s_{x}$ is a measure of ring-width variability, it can be interpreted as a measure of climatic and nonclimatic environmental influences on growth (LaMarche and Stockton, 1974).

Mean sensitivity, a parameter that was devised especially for treering analysis, is a "measure of relative difference in width from one ring to the next" and is computed as

$$
m s_{x}=\frac{1}{n-1} \sum_{t=1}^{n-1}\left|\frac{2\left(X_{t+1}-X_{t}\right)}{X_{t+1}+X_{t}}\right|,
$$

where $X_{t}$ is ring width at year $t$, and $n$ is the total number of rings (Fritts, 1976). Because $m s_{x}$ is a measure of ring width variation from ring to ring, it is commonly interpreted as the response of trees to growth limiting factors (Cook, 1976), especially climatic factors. For this reason, chronologies having a relatively high mean sensitivity are the most desirable.

First order serial correlation, or autocorrelation, herein referred to as serial $\mathrm{R}$, describes the degree of correlation or dependence between the width of 1 year's ring and that of the preceding year. The relationship is assumed to be largely biological, depending mainly on stored photosynthates and the persistence of needles on conifers, which can influence growth in following years. Commonly this persistence does not exceed 2 or 3 years, only affecting high frequency variance (less than 8-year cycles) and not the low frequency variance attributed to climatic trends (Fritts, 1976).

In the ANOVA subroutine of INDXA, ring-width variance is partitioned into components $\mathrm{Y}, \mathrm{YT}$, and YCT according to probable source, using the modified analysis of variance method described in detail by Fritts (1976). The $Y$ component represents ring-width variance in common among all cores in the collection and is assumed to be due to climate. Another component, YT, accounts for differences in variance between trees within the collection. This component can be high if the site lacks homogeneity. In this case the uneven distribution of environmental factors affects the growth of each tree individually. A third component, YCT, is the variance attributed to irregularities between cores of the same tree. This can be caused by the effects of competition, crown size, and uneven distribution of photosynthates (Fritts, 1976). For these reasons the last two components are often referred to collectively as the error or unexplained variance with respect to climatic signal.

Stockton (1973) suggested the following as a priori ranges that indicate strong climatic signal in chronologies for arid sites: mean sen- 
sitivity, 0.35-0.45; standard deviation, 0.35-0.45; serial $\mathrm{R}, 0.20-0.30 ; \mathrm{Y}$, 0.60-0.70; YT, 0.15-0.25; YCT, 0.05-0.15. Cook (1976) felt, however, that these values can only be loosely applied to tree-ring chronologies from eastern sites.

The calculated statistics for the chronologies used in this study are presented in table 2 along with Cook's results for hemlock in New York (Cook, 1976). In almost all cases the values are much different from those presented by Stockton (1973). They do, however, agree with results reported for other collections in the eastern United States (DeWitt and Ames, 1978). The serial $\mathrm{R}$ for the chronologies is fairly high, indicating considerable dependence of ring width on values of the previous year. Mean sensitivity is good (for the East) in all cases except at Ramseys Draft. Similarly, the standard deviation for Ramseys Draft is much lower than that of the other chronologies. Consequently, this chronology was expected to be the least climatically sensitive of the three.

TABLE 2.-Summary of chronology statistics by site

[For comparison, data for New York from Cook (1976) are included]

\begin{tabular}{|c|c|c|c|c|}
\hline Statistic & $\begin{array}{c}\text { Burling } \\
\text { Tract }\end{array}$ & $\begin{array}{l}\text { Hemlock } \\
\text { Springs }\end{array}$ & $\begin{array}{c}\text { Ramseys } \\
\text { Draft }\end{array}$ & New York \\
\hline Serial R & 0.5569 & 0.5755 & 0.4727 & 0.5168 \\
\hline Mean sensitivity & .1596 & .1710 & .1320 & .1676 \\
\hline Standard deviation & .2051 & .2027 & .1758 & .2139 \\
\hline $\begin{array}{l}\text { Variance within trees } \\
\text { (YCT) }\end{array}$ & .3259 & .5683 & .5886 & .4576 \\
\hline $\begin{array}{l}\text { Variance between trees } \\
\text { (YT) }\end{array}$ & .3028 & .1722 & .2125 & .1866 \\
\hline Variance in common $(\mathrm{Y})$ & .3710 & .2492 & .2254 & .3565 \\
\hline
\end{tabular}

The variance components are the most reflective of the quality of each chronology. Variance between cores (YCT) is high for Hemlock Springs and Ramseys Draft, suggesting considerable influence by competition. This seems to contradict the widely accepted belief in the extreme tolerance of hemlock to suppression and competition (Hough, 1936). The YCT for Burling Tract is much lower. Between tree variance (YT) for Burling Tract is correspondingly higher, suggesting much greater site heterogeneity than at other locations. Because variance in common $(\mathrm{Y})$ is considerably higher at Burling Tract than at the other two sites, we might expect this chronology to be the most climatically sensitive of the three.

The Burling Tract hemlock are probably subjected to more limiting conditions. Low elevation of the site results in a much higher mean maximum temperature for July. Compared with Burling Tract, Hemlock Springs has both greater mean annual rainfall and lower July 
temperature, whereas Ramseys Draft's mean July temperature is lower but mean annual precipitation is about the same. The combination of lower precipitation and higher temperature is assumed to result in greater stress and climatic sensitivity in the Burling Tract trees.

\section{FORMATION OF A MODEL OF THE GROWTH-CLIMATE RELATIONSHIP}

Although it was determined in advance that the July PDSI would be the climatic variable with which to work, it was still deemed advisable to form a model of the tree growth-climate relationship before attempting to reconstruct the prior July PDSI. This was necessary in order to further justify the selection of the July PDSI by basing it on a more complete understanding of the growth response of the trees to monthly temperature and precipitation. The greatest success in understanding this biological relationship has been through responsefunction analysis. In the response-function procedure, transformed monthly temperature and precipitation data and lagged tree-growth variables are used to predict tree growth using stepwise multiple regression. The climatic variables are transformed to principal components and then to eigenvector amplitudes by a procedure to be explained later. This is done to transform the climatic data into independent variables. From the multiple regression procedure a set of regression coefficients are determined, which when weighted in terms of the original climatic data, can be interpreted as the response in tree growth to each monthly climatic variable (Fritts and others, 1970). Collectively these weighted regression coefficients make up the response function. Using the response function it is possible to determine the months in which growth is most limited by both temperature and precipitation. From these the best month for which PDSI can be estimated is decided.

After determining the month for which PDSI is to be estimated, a multiple regression equation is set up so that lagged growth variables can be used to predict PDSI. Also, the relationship between lagged growth at each site and PDSI for each climatic division can be determined using correlation analysis. This is used to establish a basis for including growth variables from several sites as predictors of PDSI in the multiple regression equation.

\section{RESPONSE FUNCTION}

For the response-function analysis of hemlock at the Burling Tract, total monthly rainfall and monthly average temperature at Washington, D.C., for the period 1866-1976 were used as predictors of the tree-growth indices. A 17-month climatic period for year $t$ was 
used, beginning in May of the prior year and ending in September of the current year. This was done based on the assumption that climatic and biological factors that occur in the prior months can influence growth in the current season. The climatic variables were converted to eigenvector amplitudes and along with three prior year growth variables were regressed against tree growth indices using stepwise multiple regression. The 3 years of prior growth were included to account for the effects of serial correlation. Eigenvector amplitudes were derived from principal components of the climatic variables and were used because orthogonal variables can be much better predictors than untransformed data (Fritts and others, 1970).

Principal components, or eigenvectors, are calculated from a matrix of climatic variables that have been normalized in the following manner:

$$
F_{t}=\frac{x_{t}-m_{x}}{s_{x}},
$$

where $F_{t}$ is a normalized element of matrix $\boldsymbol{F}$ at time $t, x_{t}$ is the precipitation and temperature in each of the 17-months related to year $t ; m_{x}$ is the mean of $x_{t}$; and $s_{x}$ is the standard deviation of $x_{t}$. A correlation matrix is then derived as

$$
\boldsymbol{C}=\frac{1}{n} \boldsymbol{F} \boldsymbol{F}^{\prime}
$$

where $\boldsymbol{F}$ is the matrix of normalized data, having the variables arranged in rows with $n$ yearly observations in the columns, and $\boldsymbol{F}^{\prime}$ is its transpose. An eigenvector matrix, $\boldsymbol{E}$, is then derived from the relationship

$$
C E=E L,
$$

where $\boldsymbol{L}$ is the matrix of eigenvalues. Each eigenvalue is proportional to the variance reduced by the eigenvector to which it corresponds. Eigenvectors are orthogonal representations of the original variables, each accounting for a certain part of the variance of the data. Eigenvector amplitudes, or factor scores, are then calculated as

$$
\boldsymbol{A}=\boldsymbol{E}^{\prime} \boldsymbol{F},
$$

where $\boldsymbol{A}$ is the matrix of eigenvector amplitudes and $\boldsymbol{E}^{\prime}$ is the transpose of $\boldsymbol{E}$. The amplitude matrix is therefore assumed to be representative of the data in matrix $\boldsymbol{F}$ (Morrison, 1967; Fritts, 1976).

Multiple regression, with stepwise inclusion of the eigenvector amplitudes of climatic data and prior growth variables, was used to predict tree growth. At each step in the procedure an additional 
computation was made without the prior growth variables. The simplified form of the multiple regression equation is

$$
\hat{x}_{\mathrm{t}}=b_{0}+\sum_{i=1}^{34} b_{i} A_{i t}+\sum_{j=1}^{3} b_{34+j} X_{t-j}
$$

where $\hat{x}_{t}$ is estimated tree growth in year $t ; b_{0}$ scales the estimate to the mean of $X ; b_{i}$ and $b_{34+j}$ are partial multiple regression coefficients; $A_{i t}$ are the eigenvector amplitudes of the $i=1$ to 34 monthly temperature and precipitation variables in year $t$; and $X_{t-j}$ is tree growth in 1,2, and 3 prior years. The variance explained by climatic variables alone was subtracted from that explained by climate and prior growth together to estimate the variance in the growth indices due to prior growth. For the Virginia hemlock, the total variance reduced $\left(\bar{R}^{2} \times 100\right)$ was 60.4 percent. Variance due to climate was 28.0 percent, and that due to prior growth was 32.4 percent. In New York climate accounted for 50.1 percent of the variance, with none due to prior growth (Cook, 1976).

The growth responses of hemlock to climate in Virginia and New York are plotted in figure 2, with months that had a significant effect at the 95 percent confidence level indicated. The monthly values are assumed to represent departures of the standardized indices of growth from the mean and collectively are referred to as the response function, $\boldsymbol{T}$. This was derived from the relationship

$$
\boldsymbol{T}=\boldsymbol{B} \boldsymbol{E}^{\prime}
$$

where $\boldsymbol{B}$ represents the regression coefficients calculated in the multiple regression procedure, and $\boldsymbol{E}^{\prime}$ is the transpose of the matrix of eigenvectors of the climatic data (Fritts and others, 1970). A positive value for any monthly climatic variable indicates a positive tree-growth response for that climatic variable in that month. Negative values indicate a negative growth response.

Comparison of the hemlock response function from New York and Virginia indicates many similarities. The main departure lies with the May and June response to the precipitation of the current year. At the Burling Tract, hemlock apparently are not as stressed. Hemlocks in New York were growing on well drained talus slopes providing xeric conditions in spite of consistently good rainfall (Cook, 1976). The much more sheltered Burling Tract site, like most southern hemlock sites, probably has normally abundant soil moisture, so the response to rainfall was not as dramatic. This, however, was not felt to be a considerable problem because during periods of drought the soil moisture at Burling Tract would not likely be maintained.

The response to temperature in growth during the May to July period at the Burling Tract was negative, whereas the response to rainfall was positive. It is therefore assumed that high temperatures and (or) low 


\section{Response Function}

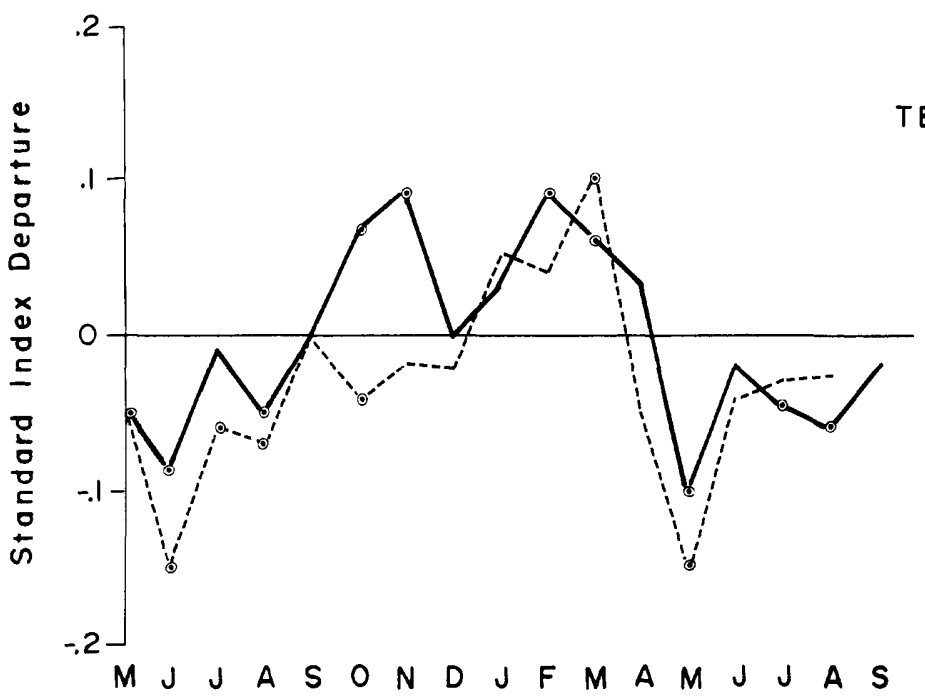

New York-....... Virginia

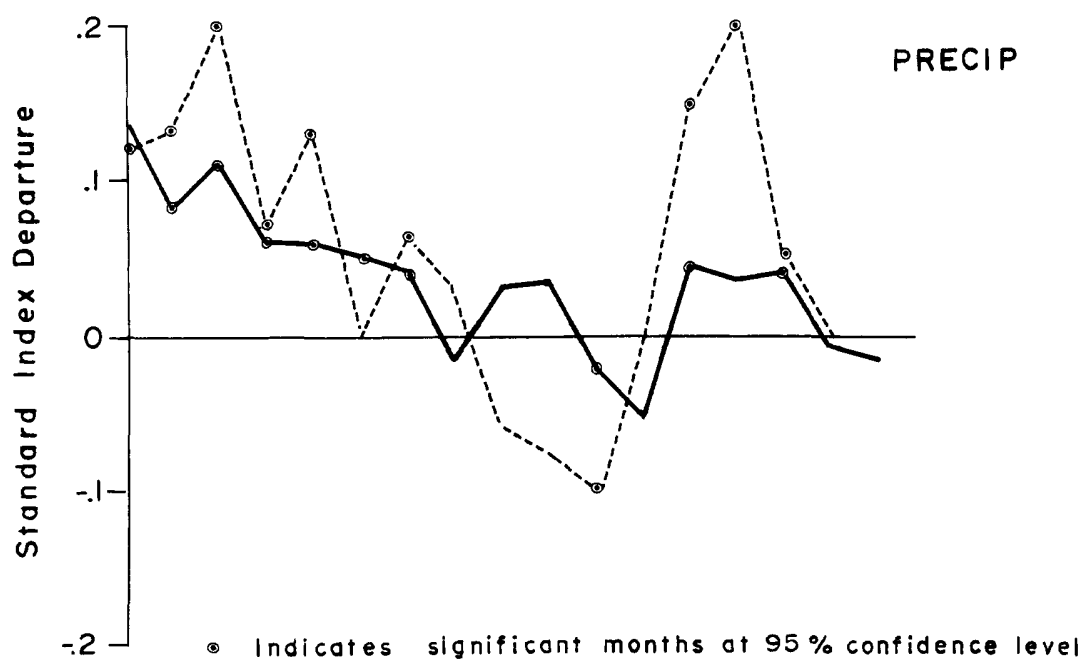

FIGURE 2.--Plots showing response-function results. The response to prior growth alone is not shown. Virginia data are for Burling Tract trees. New York data are from Cook (1976).

rainfall during this period would result in reduced growth. Because the July PDSI is largely dependent on temperature and precipitation during this same period, reconstruction of the July PDSI from tree-growth data seemed promising. 


\section{MULTIPLE REGRESSION EQUATION}

In the response-function analysis a total of 34 climatic variables and three prior year growth variables were used to predict growth in the current growing season. For reconstruction of the July PDSI, this relationship had to be turned around so that growth variables were used in a stepwise multiple regression equation to predict one climatic variable. Because temperature and precipitation limit growth, this seemed to support selection of a climatic variable (PDSI) that incorporated them both.

In order for this multiple regression equation to make sense biologically, several other factors were incorporated into the growthclimate relationship. Photosynthates may be retained in the tree during the winter dormant period and used for growth during the following year. Also, needles of hemlock are retained on the tree and remain photosynthetically active for about 3 years (Hough, 1965). Because of the influence of climate on the production of photosynthates and needles, the climate of a given year is assumed to affect growth to some degree in subsequent years. Therefore growth indices in subsequent years were included in the multiple regression equation to predict previous climate. This was done by lagging the chronology by 3 years.

Another biological factor used was the inherent growth trend of the trees (Fritts, 1976). To incorporate this, growth from one year was used to predict climate of the following year. This was also assumed to account for serial correlation in the PDSI series. The PDSI value for the current year can be a measure of soil moisture and therefore the PDSI in the following year. Similarly, growth in year $t-1$ is affected by the PDSI of year $t-1$, so it may be valuable as a predictor of the PDSI for the following year $(t)$ (Stockton and others, 1978).

The simplified form of the multiple regression equation used is

$$
\hat{y}_{t}=b_{0}+b_{1} X_{t+2}+b_{2} X_{t+1}+b_{3} X_{t}+b_{4} X_{t-1} \text {, }
$$

where $\hat{y}$ is the estimated July PDSI of year $t ; b_{0}$ scales the equation to the mean of $y ; b_{1}, \ldots, b_{4}$ are regression coefficients; and $X_{t}$ is a measure of tree growth in year $t$. In this form, all the previously discussed variables in the growth-climate relationship are represented. However, in order to more completely represent the climate (PDSI) for an entire climatic division, growth variables from more than one site are to be added to the regression equation. The basis for establishing a relationship between climate and growth indices from various sites is to be derived from cross-correlation analysis of the lagged chronologies and the July PDSI for each division and the State average. 
Correlations were computed for the period 1931-75 to determine the relationship between the lagged growth at each site, between sites, and between lagged growth and the July PDSI for the Northern Virginia and Central Mountain climatic divisions, as well as for the average of all six Virginia climatic divisions. The results are presented in table 3. High correlations between lagged growth at the same site reflected the high first order serial correlation in each chronology. The correlation between chronologies was also high (greater than 0.60 ), indicating that the trees have been responding in a similar manner to the macroclimate. This high intercorrelation was encouraging, suggesting that all three chronologies would be useful in estimating the divisional July PDSI.

The most important results were the correlations between lagged growth and the July PDSI for each climatic division. Burling Tract showed the highest correlation with each PDSI series. It was interesting that year $t+1$ was most highly correlated with the Northern Virginia PDSI and the Virginia Average PDSI, whereas year $t$ was highly correlated with the Central Mountain climatic division PDSI. Both Hemlock Springs and Ramseys Draft had highest correlations with each PDSI series at year $t$. Hemlock Springs had the lowest correlations, at only 0.245 with the Central Mountain PDSI at year $t$, at its highest $R$ value. It was expected from these results that the Burling Tract chronology would be the best predictor of the July PDSI for each climatic division. Ramseys Draft and Hemlock Springs were expected to account for smaller parts of the variance.

\section{CALIBRATION OF THE TREE-GROWTH RECORD WITH THE CLIMATIC RECORD}

After the tree growth-climate relationship has been determined and expressed as a multiple regression equation, it is possible to describe this relationship in a mathematical form. Through multiple regression analysis, a set of regression coefficients are computed that describe the mathematical relationship between the tree-growth variables and the climatic variable for the period in which their records overlap. These regression coefficients therefore "calibrate" the longer record of tree growth with the much shorter climatic record. Estimates of the climatic variable can then be computed for the time period equal to the length of the tree-growth record, using the regression coefficients.

To employ this approach to estimate antecedent climatic variables some basic assumptions are made. A linear relationship between tree growth and climate must be assumed in order to use multiple linear regression. It is further assumed that this relationship is constant. In 


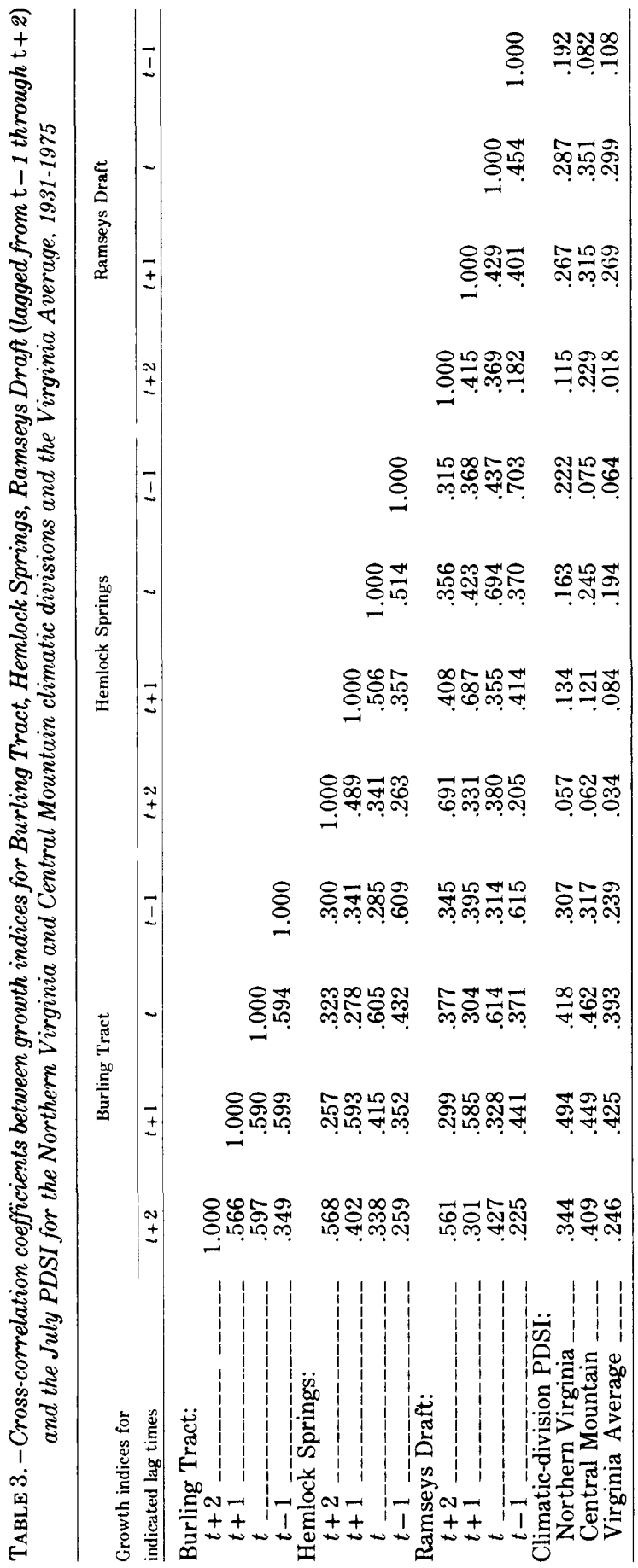


other words, the trees would respond to climate during any prior time period in the same manner and with the same magnitude as they did during the calibration period.

\section{METHODS OF CALIBRATION}

The regression coefficients of the previously discussed multiple regression equation were solved for by substituting in the known values for the PDSI and tree growth. This was done using the Statistical Analysis System (SAS) computer programs (Barr and others, 1976). The order in which computer programs and procedures were used in determining regression coefficients and reconstructing the PDSI are diagrammed in a flow chart (fig. 3).

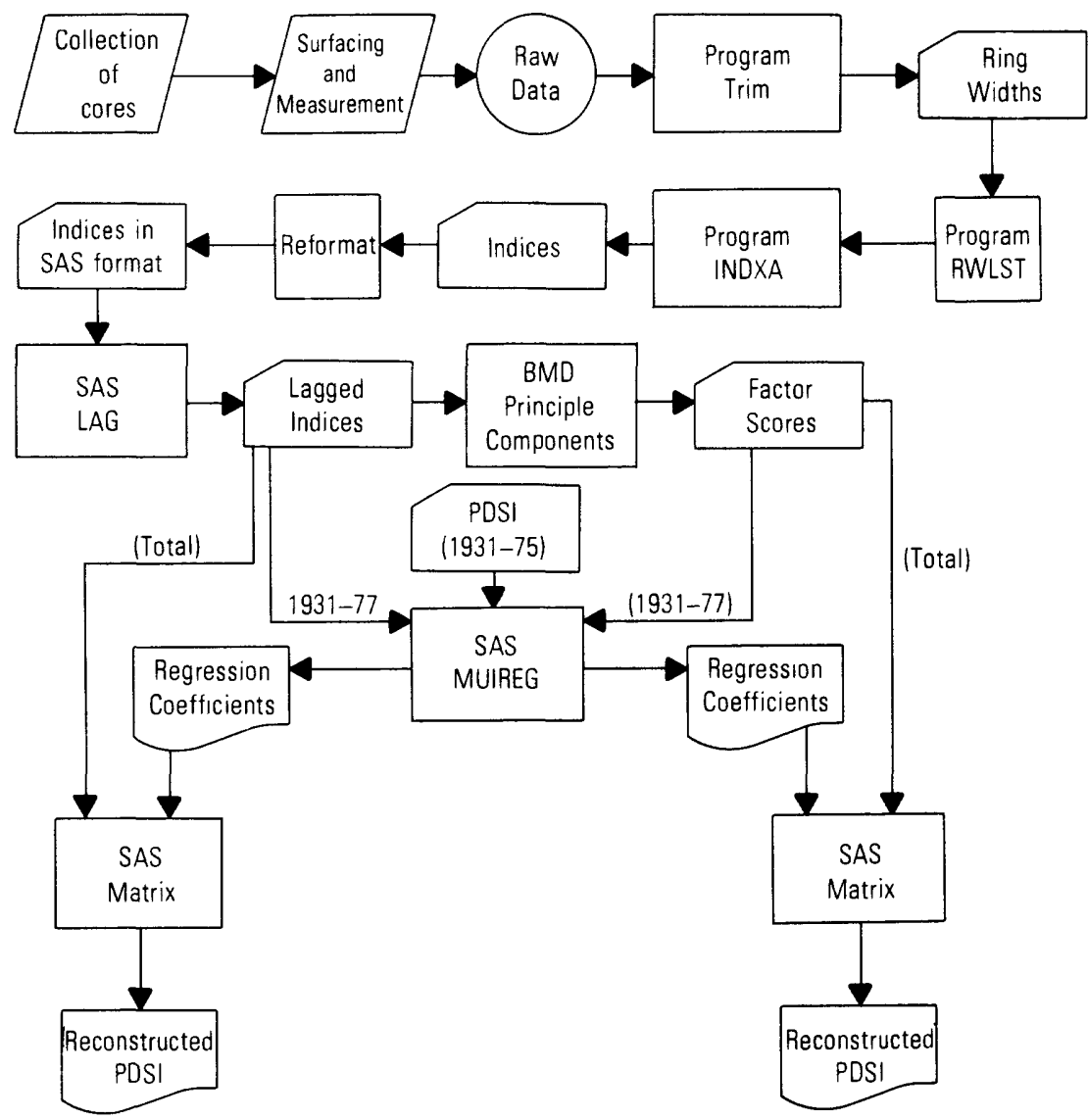

FigURE 3. - Flow chart for procedures used in making statistical estimates of the July Palmer drought-severity index. SAS is the Statistical Analysis System computer program package, BMD is the Biomedical Computer Programs package, RWLST is a ring-width plotting program, and INDXA is a program used to convert ring widths to indices. 
The indices of growth computed by the INDXA program (see Measurement and Computer Processing, p. 13) were reformatted and entered into the computer as an SAS data set. The indices were then lagged, and various combinations of the three chronologies (Burling Tract, Hemlock Springs, and Ramseys Draft) were calibrated with the July PDSI for the period 1931-75 using the SAS multiple regression program (STEPWISE), which seeks the maximum improvement in the coefficient of multiple determination $\left(R^{2}\right)$ at each step. This program first selects the best one-variable model, that is, the single growth variable most highly correlated with the PDSI variable, then the best two-variable model, three variable model, an so on, until all the predicfor variables are used (Barr and others, 1976). At each step a set of regression coefficients is calculated. Because the $R^{2}$ calculated by the program does not reflect the loss in degrees of freedom as variables are added at each step, an adjusted $R^{2},\left(\bar{R}^{2}\right)$, was calculated using the program results:

$$
\bar{R}^{2}=R^{2}-\left[\begin{array}{ll}
\frac{K-1}{N-K} & \left(1-R^{2}\right)
\end{array}\right],
$$

where $K$ is the number of variables used and $N$ is the total number of years (Stockton and others, 1978). This statistic represents the proportion of explained variance. That regression step that had the highest $\bar{R}^{2}$ was selected for use in the subsequent reconstruction. Thus, the equation selected did not contain all possible variables.

Regressions were also calculated using eigenvector amplitudes, or factor scores of the lagged growth indices, as the predictors. Principal components and factor scores of the matrix of lagged growth indices were calculated using the Biomedical Computer Program (BMD) (Dixon, 1976). Those factor scores that cumulatively explained 85-90 percent of the total variance were retained for use in the regression equation. The resulting data set of factor scores are assumed to be statistically independent (orthogonal), so a much more stable reconstruction can be expected (Cook and Jacoby, 1977). Furthermore, according to Fritts (1976), patterns of variance of the growth indices are concentrated in the first few principal components, thereby reducing the number of predictor variables that need to be used in the regression equation. This is advantageous because large numbers of predictor variables can result in overfitting and an unrealistically high $R^{2}$.

Another approach was employed in studying the relation of Burling Tract tree-growth indices with the Northern Virginia July PDSI. Factor scores of the growth indices of twelve individual trees were computed instead of factor scores of the lagged chronology. The factor 
scores were then lagged and used as predictor variables in the regression procedure. Owing possibly to lack of site homogeneity, certain individual trees may have been more highly correlated with the climaticdivision PDSI than were others. It was felt that factor scores would retain more of the variance due to climate for the Burling Tract trees and thereby increase the strength of the climatic signal. This strategy has been employed experimentally with growth indices of bald cypress to reconstruct lake-level data for Lake Drummond, although principal components and factor scores were not used in that study (Phipps, oral commun., 1979). Again the regression and reconstruction procedures previously outlined were followed.

Although eigenvector amplitudes are widely used in dendroclimatology as predictors in multiple regression procedures, there remain questions as to the validity of computing these from lagged chronologies. Some research using eigenvector amplitudes of the same chronologies with lagging done either before or after determination of the amplitudes has produced similar results (Stockton, oral commun., 1979; Cook, oral commun., 1979). Little is known of the effects on the amplitudes due to using such highly correlated data in the principal component calculations. It has been demonstrated, however, that by using either method, verifiable estimates of prior climatic and hydrologic variables can be obtained (Fritts, 1976; Cook and Jacoby, 1977; Stockton and others, 1978).

\section{DISCUSSION OF REGRESSION RESULTS}

\section{LAGGED INDICES}

For each climatic division several regressions were run using various combinations of the lagged chronologies. As was expected from the results of the cross-correlations between the lagged chronologies and climate, the computed $R^{2}$ for each regression varied considerably depending on which chronologies were used (table 4).

The $\bar{R}^{2}$ of the regressions with Northern Virginia divisional PDSI for July ranged from $\bar{R}^{2}=0.014$ with the Hemlock Springs lagged chronology alone to $\bar{R}^{2}=0.145$ with all three lagged chronologies. The Burling Tract lagged chronology as expected was the predictor with an $\bar{R}^{2}=0.218$ when entered as the only growth variables in the regression equation. Hemlock Springs was the worst predictor, even though this site is in the Northern Virginia division. It is suspected that the combination of higher rainfall and lower temperatures at this site has resulted in growth responses that do not fit the response-function results found for the Burling Tract. In other words, growth at Hemlock Springs may be better correlated with a climatic variable other than the July PDSI. Ramseys Draft was also a poor predictor, possibly for similar reasons. 
TABLE 4. -Variation of unadjusted and adjusted maximum $R^{2}$ for each regression model for the period 1931-1975 and for combination of chronologies used

[The $R^{2}$ and $\bar{R}^{2}$ of the combination used for the reconstruction is shown in the right hand column. BT, Burling Tract; HS, Hemlock Springs; RD, Ramseys Draft]

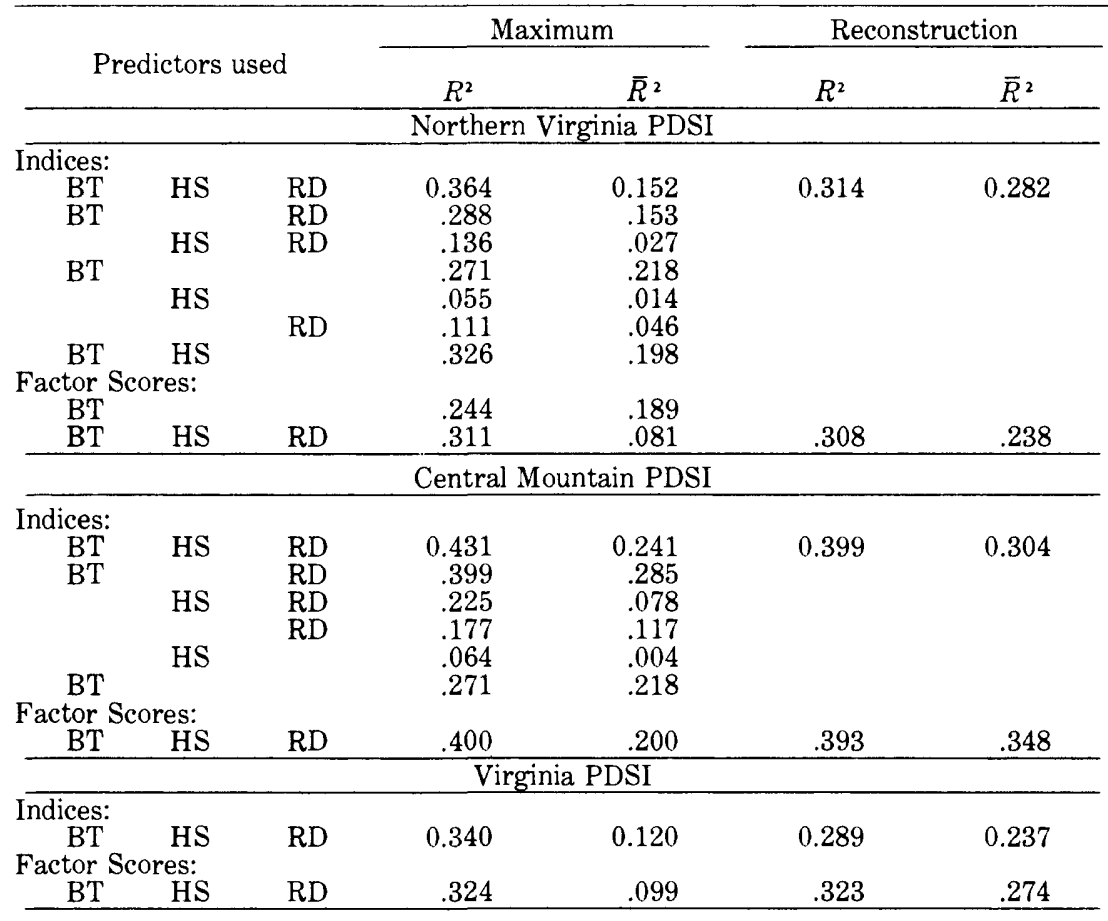

The best regression equation for the Northern Virginia July PDSI included all the chronologies as predictors. At the particular step with the highest $\bar{R}^{2}$, only three of the twelve possible variables were used. The resulting equation accounted for 28.2 percent $\left(\bar{R}^{2} \times 100\right)$ of the variance for the calibration period, 1931-1975. Table 5 summarizes those variables included in the equation and the calculated $\bar{R}^{2}$. Growth at year $t+1$ for Burling Tract, year $t-1$ for Hemlock Springs, and year $t$ for Ramseys Draft had the highest individual correlations between each site and the Northern Virginia divisional PDSI (table 3). It is interesting to note that growth at year $t+1$ for Burling Tract and year $t$ at Ramseys Draft were chosen in the regression procedure (table 5).

Regressions with the Central Mountain divisional July PDSI and indices of growth yielded results similar to those for Northern Virginia (table 4.) The reconstruction equation accounted for 30.4 percent $\left(\bar{R}^{2}=\right.$ 0.304) of the PDSI variance and used only seven of twelve possible variables. These seven variables were growth at years $t+2$ and $t-1$ at both Burling Tract and Hemlock Springs and years $t+1, t$ and $t-1$ at Ramseys Draft. 
TABLE 5. -Combinations of variables resulting from the calibration of tree rings with the divisional PDSI for the period, 1981-1975

[The first three models used lagged chronologies as variables, the second three models used factor scores of lagged chronologies, and the final model used lagged factor scores of individual tree indices]

\begin{tabular}{|c|c|c|}
\hline Variables used ' & $\begin{array}{c}\text { Percent variance } \\
\text { reduced } \\
\left(\bar{R}^{2} \times 100\right) \\
\end{array}$ & $\begin{array}{l}\text { Regional } \\
\text { PDSI } \\
\text { reconstructed }\end{array}$ \\
\hline \multicolumn{3}{|l|}{ Lagged indices } \\
\hline $\begin{array}{l}\mathrm{BT}(t+1), \mathrm{HS}(t+1), \mathrm{RD}(t) \\
\mathrm{BT}(t+2), \mathrm{BT}(t-1), \mathrm{HS}(t+2) \\
\mathrm{HS}(t-1), \mathrm{RD}(t+1), \mathrm{RD}(t), \\
\mathrm{RD}(t-1) \\
\mathrm{BT}(t+1), \mathrm{HS}(t+1), \overline{\mathrm{HS}}(t-1), \overline{\mathrm{RD}}(t)\end{array}$ & $\begin{array}{l}30.4 \\
23.7\end{array}$ & $\begin{array}{l}\text { NV } \\
\text { CM } \\
\text { VA }\end{array}$ \\
\hline \multicolumn{3}{|l|}{ Eigenvector $^{3}$} \\
\hline $\begin{array}{l}1,2,3,5,7 \\
1,2,3,5 \\
1,2,3,5\end{array}$ & $\begin{array}{l}23.8 \\
34.8 \\
27.4 \\
\end{array}$ & $\begin{array}{l}\text { NV } \\
\text { CM } \\
\text { VA }\end{array}$ \\
\hline \multicolumn{3}{|l|}{ Eigenvector ${ }^{3}$} \\
\hline $\begin{array}{l}3,5,8,12,13,15,16 \\
17,19,21,24\end{array}$ & 63.6 & NV \\
\hline
\end{tabular}

The Virginia Average July PDSI was derived by averaging the yearly observations for each of the six climatic divisions for the period 1931-1975. Only one regression combination was used with this climate record. All three lagged chronologies were entered into the regression program providing a total of twelve potential variables. The best equation contained four variables and accounted for 23.7 percent $\left(\bar{R}^{2}=\right.$ 0.237) of the PDSI variance (table 5).

\section{EIGENVECTOR AMPLITUDES}

To avoid using variables that were not statistically independent, the lagged chronologies were converted to orthogonal variables by calculating principal components and factor scores of the three lagged chronologies. These were used as predictors in the regression equation.

Of the twelve eigenvectors, the first seven retained 90 percent of the variance in tree growth. These seven were then converted to factor scores and used as predictor variables in regression with the July PDSI for each of the three climatic divisions for the period 1931-75. The results of the regressions are given in table 5. For the Northern Virginia PDSI, 23.8 percent $\left(\bar{R}^{2}=0.238\right)$ of the variance was explained using five of the seven variables. In regressions using growth indices 29.2 percent $\left(\bar{R}^{2}=0.282\right)$ of the variance was explained. Thus, use of orthogonal variables did not improve estimation of the Northern Virginia PDSI. This may be because some climatic information was discarded with those factor scores that only accounted for 10 percent of 
growth variance or, as is more likely, because only three degrees of freedom were lost using indices compared with five degrees of freedom using factor scores.

The best equation for the Central Mountain divisional July PDSI used four of seven available variables and accounted for 34.8 percent $\left(\bar{R}^{2}=\right.$ 0.348 ) of climate variance (table 5 ). With indices of growth, 30.4 percent $\left(\bar{R}^{2}=0.304\right)$ of the variance was explained using only three growth variables. This represented a 4.4 percent increase for $\bar{R}^{2}$ by using factor scores. Regressions with the Virginia Average July PDSI and factor scores produced results similar to those for the Central Mountain division. The same four variables were used in the best equation and accounted for 27.4 percent $\left(\bar{R}^{2}=0.274\right)$ or the variance. This was an increase of 3.7 percent over the results using indices of growth as predictors (table 5 ).

These results indicate that using factor scores of growth as predictors does not necessarily improve prediction. In using orthogonal variables, the largest portion of the variance is concentrated in the first few eigenvectors, so fewer variables are necessary to explain the variance. However, because only a few of the eigenvectors are used, a net loss in climatic information derived from tree growth indices can be expected. When the amount of information lost is sufficiently offset by the reduction in variables and independence of the factor scores, the trade off seems acceptable.

In an effort to determine if individual trees were more sensitive to Northern Virginia divisional climate than were the chronologies, regressions were made using lagged factor scores of growth indices from individual trees. The factor scores were calculated from unlagged individual tree-growth indices because only twenty-four variables can be entered into the computer program. For this reason the lags were made after the factor scores were calculated. The data for the Burling Tract were used, as it was the site best correlated with Northern Virginia climate. As previously discussed, the factor scores of Burling Tract trees were regressed with the Northern Virginia July PDSI. Of the twelve eigenvectors, the first six accounted for 88 percent of variance in growth. These six were lagged on themselves to create a predictor matrix of twenty-four variables. Only twelve of these were selected in the best equation, which accounted for 63.6 percent $\left(\bar{R}^{2}=\right.$ 0.636 ) of the climatic variance (table 5). Thus, the $\bar{R}^{2}$ for models predicting Northern Virginia PDSI increased from 0.238 using factor scores of all chronologies to 0.636 using factor scores of individual trees. Clearly, in this case at least, factor scores of individual trees have a considerable advantage over chronologies. Unfortunately the twelve trees used had the common period 1864-1975, thereby limiting the length of period for reconstruction. 


\section{RECONSTRUCTION RESULTS}

\section{APPARENT SHIFT IN RECONSTRUCTION}

Reconstructions, or statistical estimates, of the July PDSI were found by substituting the appropriate growth variables into the selected regression equation. In comparing the reconstructions using indices of growth as predictors (fig. 4), it may be noted that both the Northern Virginia and Virginia Average estimates contain observations that are shifted forward or backward of the Central Mountain series by 1 year. When the reconstructions using factor scores are compared with each other (fig. 5), no shift is noted. In both cases however, there was no shift in 1930. This anomaly may have been due to a shift in precipitation patterns during the 1930's, as suggested by Hayden (1979). It is more likely, however, that this was the result of selection, in the calibration procedure, of different lagged growth indices for each climatic division.

It is obvious that little of the year-to-year variance of the PDSI records was explained by using either indices of growth or factor scores as predictors $\left(\bar{R}^{2}\right.$ of 0.237 to 0.348$)$. The Northern Virginia July PDSI reconstruction using factor scores of twelve individual trees $\left(\bar{R}^{2}=0.636\right)$, shown in figure 6 , retains much more of the highfrequency variation most desirable in reconstructions; however, the low $\tilde{R}^{2}$ reconstructions based on chronologies appear to reflect lowfrequence climatic trends.

\section{DROUGHT OCCURRENCE AND VERIFICATION}

The Northern Virginia reconstruction to 1864 (fig. 6), based on growth of individuar trees, shows good agreement in pattern with the PDSI record during the calibration period (1931-75). An extreme drought estimated for 1914 seems to be the only major discrepancy in this series. Although climatic records for Washington, D.C., indicate a drought for this period, it is not recorded as being this severe. Possibly the combined environmental factors placed considerably greater stress on the trees than was reflected in the climatic data.

Washington, D.C., climate records were the only local ones long enough for verification and comparisons. The July PDSI was calculated using these data and is shown plotted over the Northern Virginia reconstruction $\left(\bar{R}^{2}=0.282\right)$ in figure 7 . It must be remembered that this reconstruction is calibrated using climate data from the entire Northern Virginia division, whereas the Washington, D.C. data are from one station. The cross correlations (table 6) show that the Northern Virginia PDSI and the Washington, D.C., PDSI are fairly well correlated $\left(\bar{R}^{2}=0.497\right)$. However, figure 6 shows that certain PDSI trends during the calibration period are opposite, particularly 

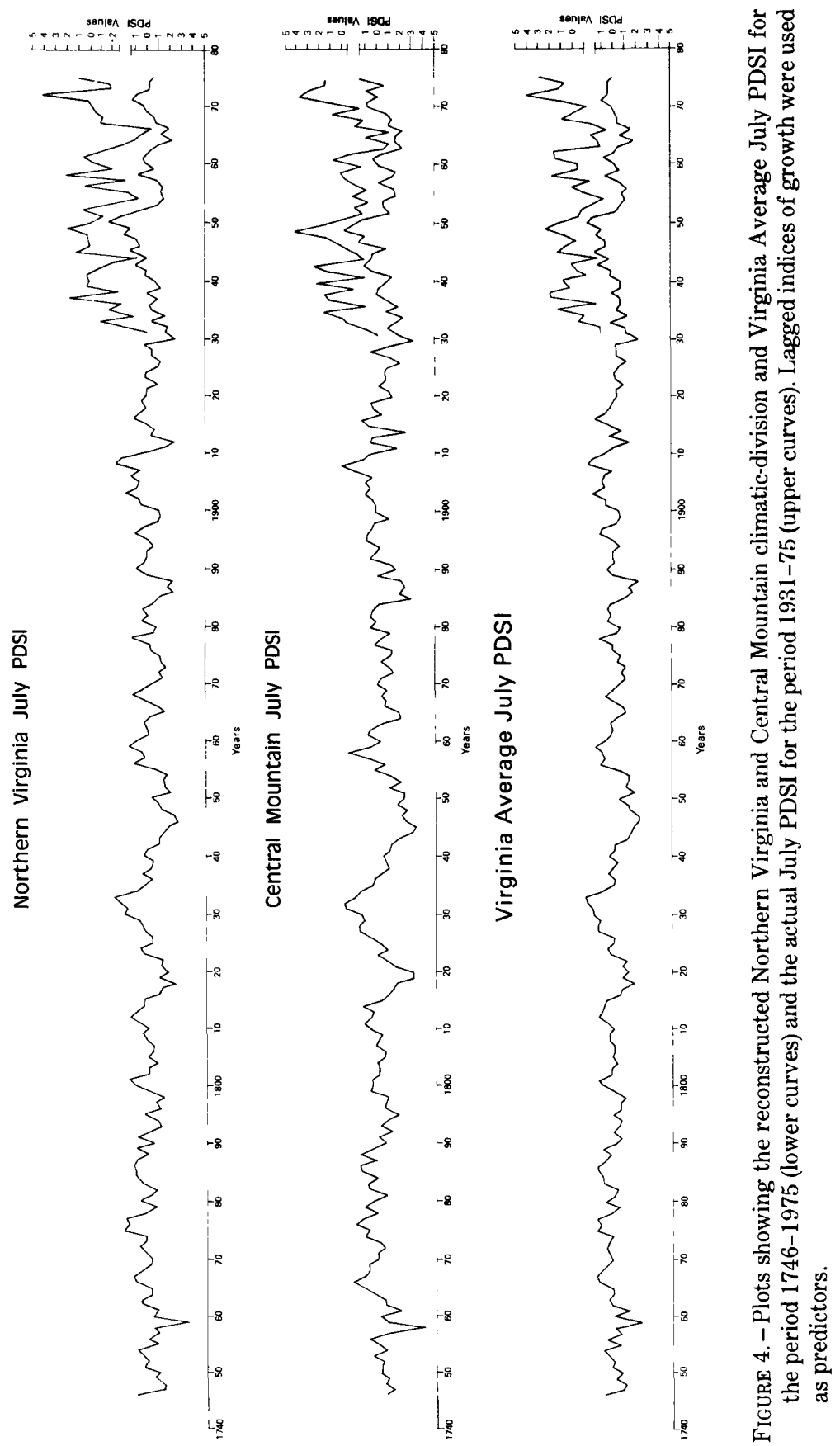

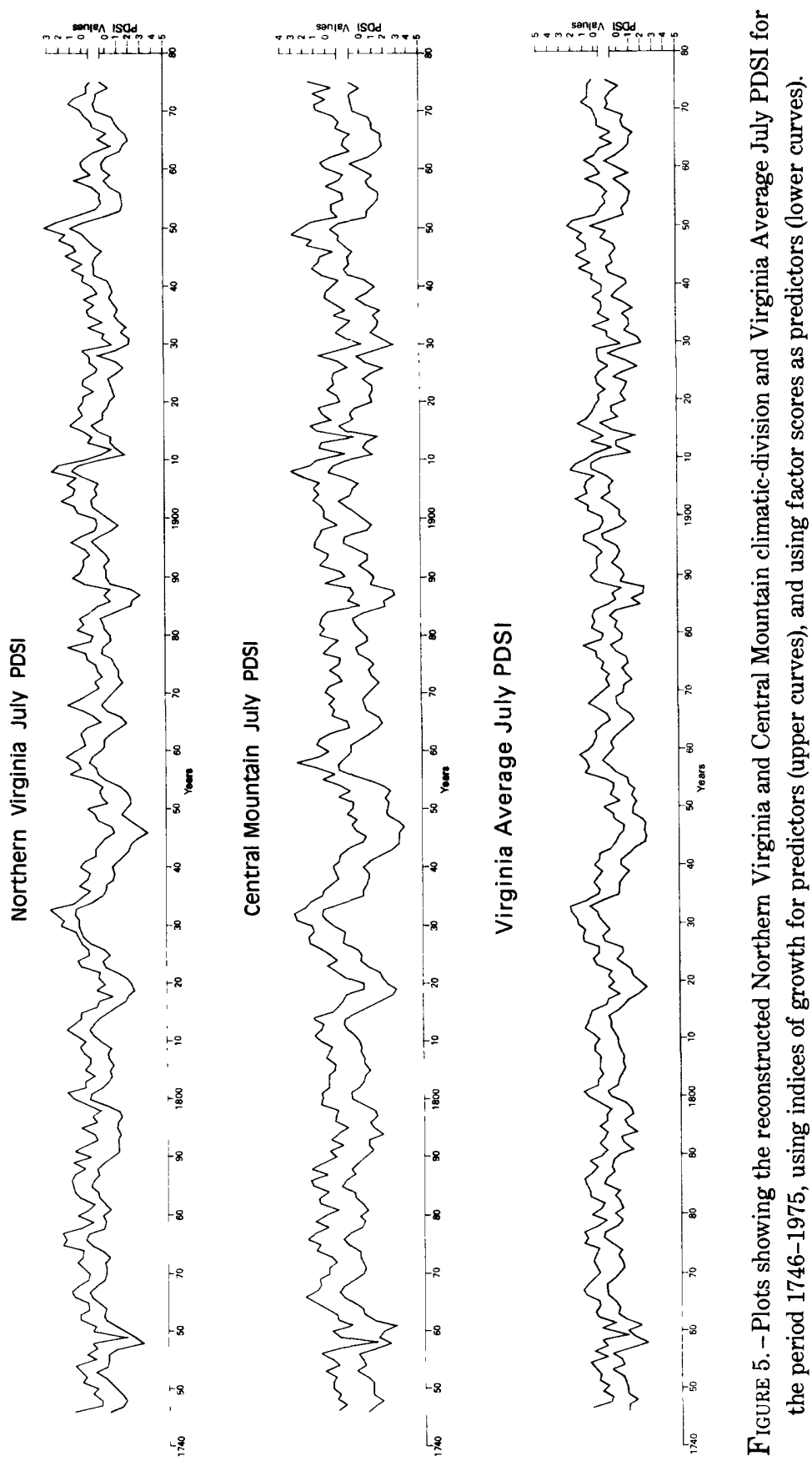

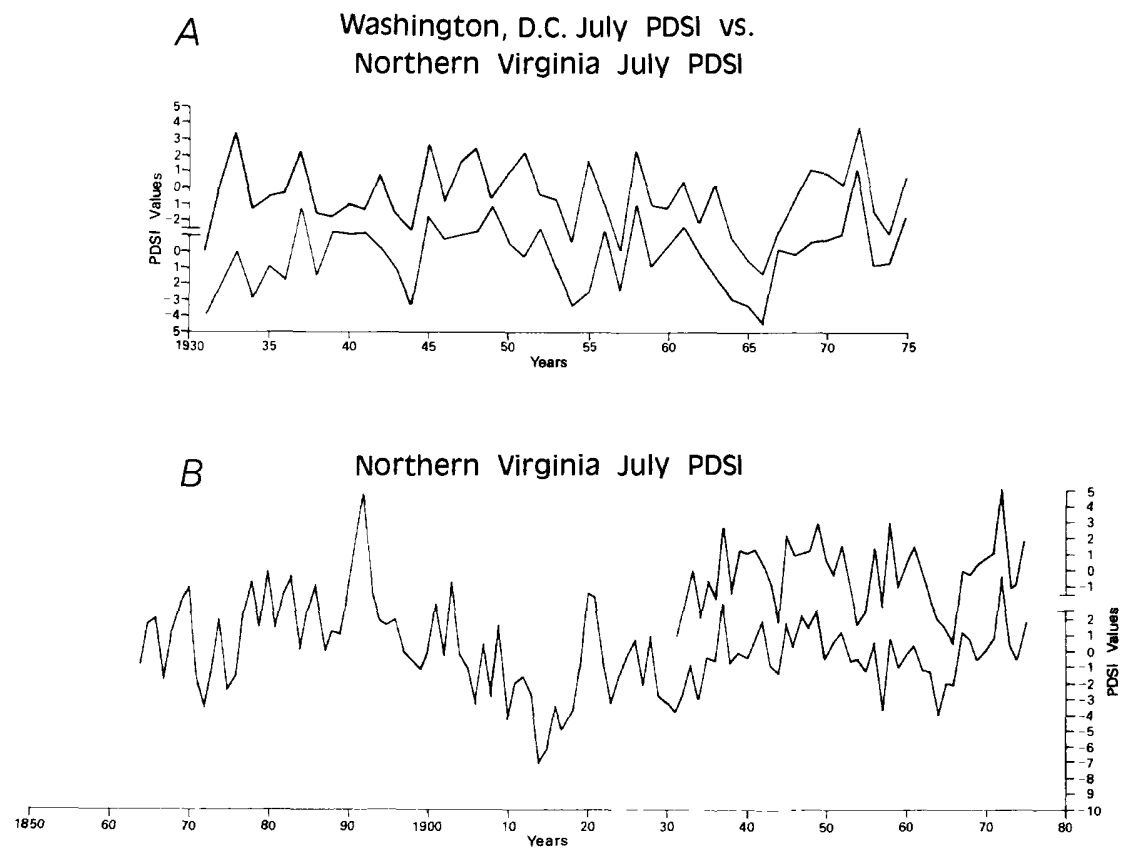

FIGURE 6. -Plots showing the actual Northern Virginia climatic-division July PDSI compared with the actual Washington, D.C. July PDSI and the estimated Northern Virginia July PDSI. $A$, The actual July PDSI for the period 1931-75 for Washington, D.C. (upper curve) and the Northern Virginia climatic division (lower curve). $B$, The actual Northern Virginia climatic-division July PDSI for the period 1931-75 (upper curve) and the reconstructed Northern Virginia climatic-division July PDSI for the period 1864-1975 (lower curve). Factor scores of the first 6 eigenvectors of growth indices of 12 Burling Tract trees were used as predictors.

around 1939-1942 and 1949-1952. For most of the observations in the reconstruction (fig. 7), the Washington, D.C., PDSI is in agreement. Although there are years where the actual climatic data do not seem to agree with the estimates, the overall climatic trend is similar.

TABLE 6. -Correlations between computed PDSI for Washington, D.C.,Northern Virginia and Central Mountain climatic divisions, and Virginia Average, for the period 1931-1975

\begin{tabular}{|c|c|c|c|c|}
\hline & $\begin{array}{l}\text { Washington, } \\
\text { D.C. }\end{array}$ & $\begin{array}{l}\text { Northern } \\
\text { Virginia }\end{array}$ & $\begin{array}{l}\text { Central } \\
\text { Mountain }\end{array}$ & $\begin{array}{l}\text { Virginia } \\
\text { Average }\end{array}$ \\
\hline Washington, D.C. & 1.000 & & & \\
\hline Northern Virginia & .705 & 1.000 & & \\
\hline Central Mountain & .429 & .575 & 1.000 & \\
\hline Virginia Average & .532 & .784 & .807 & 1.000 \\
\hline
\end{tabular}



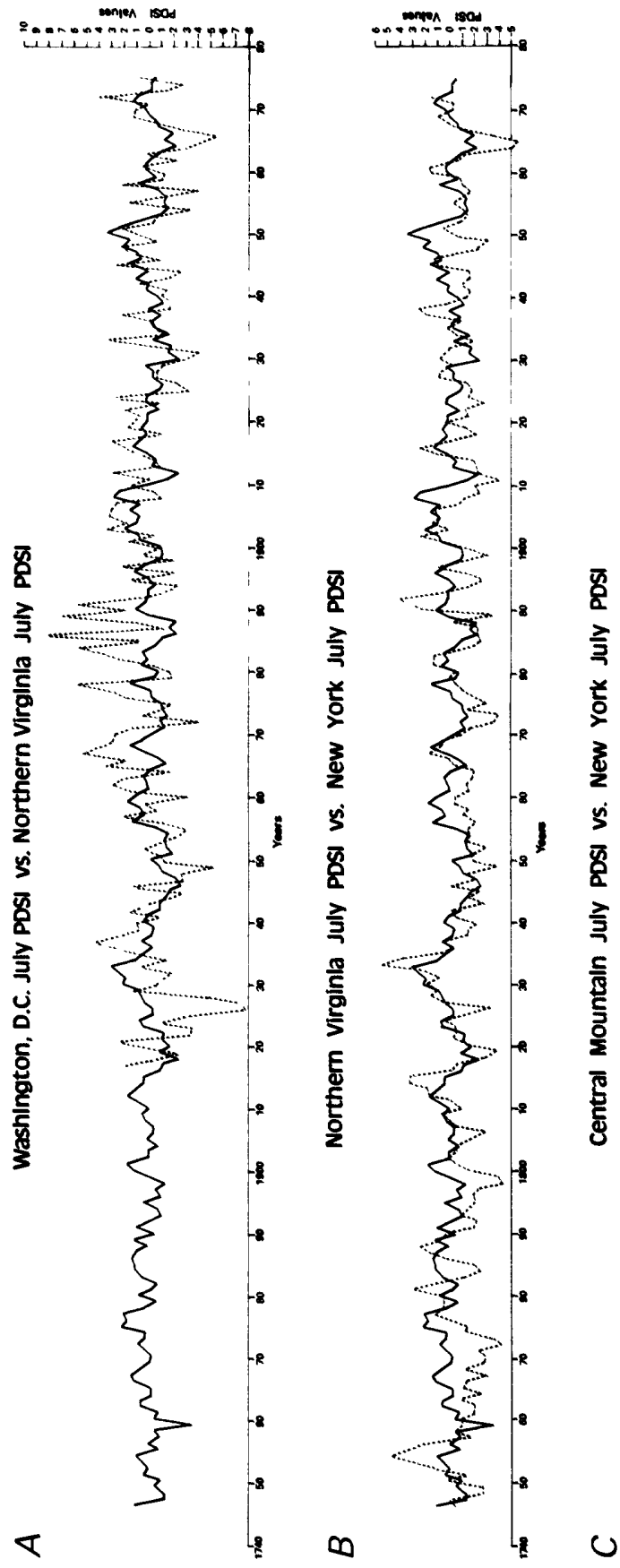

…ำn
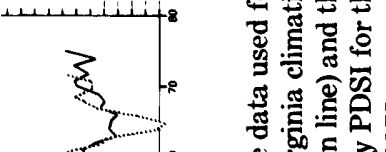

否三是

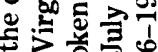

톨

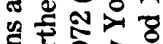

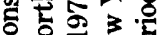

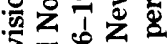
焉吉焉

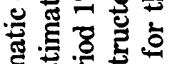

至焉荡

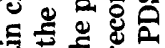

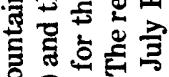

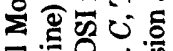

졸

둥 35 ४े 를 는든들 . केष

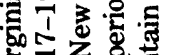
然学 $>$ 必焉 다월 焉跑焉 훙해

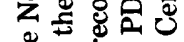

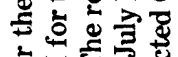

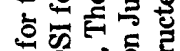

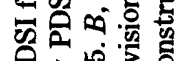
का 10 क 고군 苟记 马드용 สำ ส 蛋 ऊin $\sum$ -

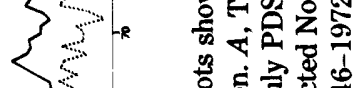

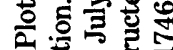
ᄂ …‥ 
The most interesting results were obtained from comparisions of the Northern Virginia and the Central Mountain climatic-division July PDSI reconstructions with the July PDSI reconstruction for New York State $\left(\bar{R}^{2}=0.54\right)$ made by Cook and Jacoby using similar techniques (1977). These comparisons are presented in figure 7. Probably the most noticeable difference between the curves in figure 7 is the much better agreement between the New York and the Central Mountain climatic division July PDSI. Because the $\bar{R}^{2}$ is much higher for the New York reconstruction ( 0.54 versus 0.304 for the Central Mountain reconstruction and 0.282 for the Northern Virginia reconstruction), many of the extremes for the New York reconstruction are of a higher magnitude.

Between 1800 and 1970, unmistakeable agreement may be noted between the New York and the Central Mountain PDSI. During this time there were nine periods of drought common to the two reconstructions (1817-22, 1842-55, 1870-75, 1885-89, 1910-14, 1920-26, 1939-41, 1952-59 and 1963-67). There are also several occurrences of localized droughts in each, particularly 1826, 1889, 1895, 1930 and 1948-49. The fact that all these but one (1930) occurred in New York suggests the possibility that the Virginia reconstruction fails to predict droughts of low intensity or short duration (1 or 2 years). Surprisingly, the 1930 drought was the only one not present in the New York reconstruction, although several sources mention a severe drought in Pennsylvania and Massachusetts in the 1929-31 period (Hough, 1936; Lyon, 1936). For the reconstructed data prior to 1800 , the climatic trends are not as well correlated. This is possibly because fewer trees were included in the chronologies for those years, with the result that climatic information in the data may have been weaker for those years. There is also the obvious alternative that during the earlier period no clear correlation existed.

As a means of examining the reconstruction of the Central Mountain July PDSI for periods of greater than normal drought occurrence, the 230-year series was divided into 50-year increments beginning in 1751 and ending in 1950. On the basis of the assumption that the distribution about the mean of the reconstructed values approximates a normal distribution, the observations were divided into three equally probable size classes, designated as dry, near normal, and wet. Near-normal years were considered to be those for which the reconstructed July PDSI values were within 0.43 standard deviation from the 1746-1975 mean. Wet years were those having a PDSI value greater than that of near-normal years, and dry years were those having a PDSI value less than that of near-normal years. For each 50-year period the number of dry, near-normal, and wet years was tallied and expressed as percentage of the total (table 7). The same determinations were made for the 1930-1975 period and for the entire record, 1746-1975. Following the 
above procedure, the $1746-1975$ period should have essentially 33 percent in each class. Results for this time period have been included as a check. Finally, the reconstruction was broken into two separate periods, $1746-1929$ and $1930-1975$.

TABLE 7. - Proportion of dry, near-normal, and wet years, in percent, which have occurred in selected time periods, based on an equal probability of occurrence between the three classes

\begin{tabular}{|c|c|c|c|}
\hline \multirow[b]{2}{*}{ Time period } & \multicolumn{3}{|c|}{ Proportion of years } \\
\hline & Dry & $\begin{array}{c}\text { Near } \\
\text { normal }\end{array}$ & Wet \\
\hline 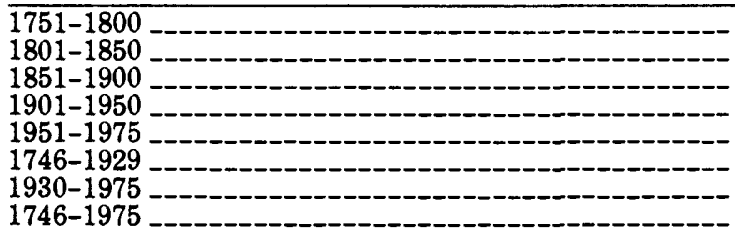 & $\begin{array}{l}26 \\
30 \\
38 \\
34 \\
48 \\
32 \\
43 \\
34\end{array}$ & $\begin{array}{l}34 \\
36 \\
40 \\
22 \\
24 \\
35 \\
22 \\
33\end{array}$ & $\begin{array}{l}40 \\
34 \\
22 \\
44 \\
28 \\
33 \\
35 \\
33\end{array}$ \\
\hline
\end{tabular}

In the first 100 years, conditions were wetter than expected, where expected represents the long-term average. During 1751-1800, 40 percent of the years were wet, while 26 percent were dry. The 1801-1850 period was closer to the expected, with only 30 percent dry years and 34 percent wet years. A dramatic change seems to have taken place during 1851-1900. Dry years were much more frequent, accounting for 38 percent of the total. Wet years showed the greatest change, constituting only 22 percent of the total. Between 1901-1950 this trend seemed to reverse, with dry years being close to the percentage expected and near-normal years occurring 22 percent of the time; also, wet years represented 44 percent of the total.

For the 1746-1929 period, dry years accounted for 32 percent of the total; near-normal years, 35 percent; and wet years, 33 percent, which is nearly the same as for the entire length of record. The recent period, 1930-1975, however, shows significantly more dry years, with drought accounting for 43 percent of the total. If the recent period is broken down further to look at the 25-year period 1951-1975, the results are even more dramatic. Of the equally probable size classes, dry years occurred 48 percent of the time. This seems to agree with Hayden's results (Hayden, 1979), which indicate much drier conditions for the Central Mountain division after 1938.

These results indicate that for the recent period, for which reliable climatic records exist, drought conditions have been much more prevalent than the average for the entire 230-year record. It is premature to draw conclusions from the data in its present form concerning the cyclical or reoccurring nature of wet and (or) dry periods. It 
must be remembered that only the low-frequency climatic trends have been estimated and verified. For this reason the reconstructed PDSI series must be considered a first-generation product that will be refined. Through more sophisticated analytical techniques and improvement of the reconstructions, it may be possible to more accurately estimate the magnitude of individual drought years.

\section{SUMMARY AND CONCLUSIONS}

Tree rings of eastern hemlock growing on steep north-facing slopes in northern Virginia were analyzed to determine climatic sensitivity of the species in this part of its range. This was part of the overall objective to reconstruct a record of the Palmer drought-severity index (PDSI) from tree-growth measurements.

Incremental core samples from trees at three sites were crossdated within and among sites. This, along with the results of analysis of variance, indicated that growth could be expected to be correlated with climate.

Response-function analysis indicated that the growth response to temperature during the May to July period was negative, whereas the response to rainfall was positive. This was taken as sufficient evidence to use the July PDSI as the dependent variable to be estimated from tree growth.

Regressions were made using indices of growth and by using factor scores as predictor variables. The factor scores were used to produce reconstructions of the July PDSI that were free from the effects of intercorrelation between predictor variables.

Regressions were also determined using factor scores of individual trees as predictors. These explained considerably more of the PDSI variance. It is believed that the climatic signal of the trees was maximized using data based on individual trees because the climatic signal contained in individual trees may explain climatic variance that is not explained if the indices of growth are averaged into a chronology. This may be an important consideration for future dendroclimatic work in the East.

The resulting reconstructions, when compared with the Washington, D.C., July PDSI and a reconstruction from New York, showed reasonable agreement for verification. In addition, several distinct periods of drought were common to both northern Virginia and New York. This suggests that more extensive reconstructions in the East may yield valuable information about widespread droughts.

Further analysis of the reconstruction of Central Mountain PDSI revealed that droughts in recent times, 1930-1975, have been much more frequent than has been the average for the total record. The earlier period, 1746-1929, apparently included approximately the same 
proportion of drought years as has the entire record, 1746-1975. The lack of high-frequency variation in the reconstruction limits the conclusions that can be drawn from the data to these generalities.

It is expected that more intensive collecting of samples within the study area, as well as inclusion of other species as predictors, will improve the reconstructions. Climatic divisional PDSI values may not be the best variable to estimate because they often are not representative of the entire climatic division. Calibration with PDSI from individual weather stations near collection sites may explain more of the year-toyear variance in reconstructions. When more of the year-to-year variation is explained, correlations with and estimation of related climatic and hydrologic variables may be possible. This could yield valuable information for planning and developing future water resources to meet the needs of both natural and man-altered systems.

\section{REFERENCES CITED}

Avery, G. S., Creighton, H. B., and Hock, C. W., 1940, Annual rings in hemlocks and their relation to environmental factors: American Journal of Botany, v. 27, p. 825-831.

Barr, F. J., Goodnight, J. H., Sall, J. P., and Hellwig, J. T., 1976, A user's guide to SAS: Raleigh, N.C., SAS Institute, Inc., 251 p.

Cleaveland, M. K., 1975, Dendroclimatic relationships of shortleaf pine (Pinus echinata Mill.) in the South Carolina piedmont: Clemson, N.C., Clemson University, unpublished MS. thesis, $189 \mathrm{p}$.

Cook, E. R., 1976, A tree-ring analysis of four tree species growing in southeastern New York State: Tucson, The University of Arizona, unpublished M.S thesis, $121 \mathrm{p}$.

Cook, E. R., and Jacoby, B. C., Jr., 1977, Tree-ring drought relationships in the Hudson Valley, New York: Science, v. 198, p. 399-401.

Crockett, C. W., 1971, Climate of Virginia: Climatography of the United States, no. 60-440, U.S. Department of Commerce, 25 p.

Cutter, E. G., 1971, Plant anatomy: Experiment and interpretation, pt. 2: London, Addison-Wesley, p. 85-106.

DeWitt, E., and Ames, M., eds., 1978, Tree-ring chronologies of eastern North America: Chronology Series IV, v. 6, no. 6, p. 1634-1640.

Dixon, W. J., 1976, Biomedical computer programs: Berkeley, University of California Press, p. 193-200.

Douglas, A. E., 1919, Climatic cycles and tree-growth, I: A study of annual rings of trees in relation to climate and solar activity: Washington, D.C., Carnegie Institution of Washington, v. 1, no. 289, $364 \mathrm{p}$.

Fisher, G. W., 1963, The petrology and structure of the crystalline rocks along the Potomac River near Washington, D.C.: Baltimore, Md., The Johns Hopkins University, unpublished Ph.D. dissertation, $241 \mathrm{p}$.

Fritts, H. C., 1962, An approach to dendroclimatology: Screening by means of multiple regression techniques: Journal of Geophysical Research, v. 67, p. 1413-1420.

1963, Computer programs for tree-ring research: Tree-Ring Bulletin, v. 25, p. $2-7$ 
Fritts, H. C., 1976, Tree rings and climate: London, Academic Press, 567 p.

Fritts, H. C., Blasing, T. J., Hayden, G. D., and Cutzback, J. E., 1970, Multivariate techniques for specifying tree-growth and climate relationships and for reconstructing anomalies in paleoclimate: Journal of Applied Meteorology, v. 10, p. 845-864.

Hayden, B. P., 1979, Atlas of Virginia precipitation: Charlottesville, University of Virginia Press, 165 p.

Hough, A. F., 1936, A climax forest community on East Tionesta Creek in northwestern Pennsylvania: Ecology, v. 17, p. 9-28.

1965, Eastern hemlock (Tsuga canadensis (L.) Carr.) in Fowells, H. A., ed., Silvics of forest trees of the United States: U.S. Department of Agriculture Handbook no. 271, p. 703-709.

Hough, A. F., and Forbes, R. D., 1943, The ecology and silvics of Pennsylvania high-plateau forests: Ecological Monographs, v. 13, p. 299-320.

Julian, P. R., and Fritts, H. C., 1968, On the possibility of quantitatively extending climatic records by means of dendroclimatological analysis, in Proceedings of the First Statistical Meteorology Conference, Hartford, Conn., May 1968: American Meteorological Society, p. 76-82.

LaMarche, V. C., Jr., and Stockton, C. W., 1974, Chronologies from temperature sensitive bristlecone pines at upper tree-line in Western United States: Tree-Ring Bulletin, v. 34, p. 21-45.

Lesure, F. G., and Geraci, P. J., 1977, Mineral resources of the Ramseys Draft Wilderness Study Area, Augusta County, Virginia: U.S. Geological Survey Bulletin 1397-C, $42 \mathrm{p}$.

Lyon, C. J., 1935, Rainfall and hemlock growth in New Hampshire: Journal of Forestry, v. 33, p. $162-168$.

1936, Tree-ring widths as an index of physiological dryness in New England: Ecology, v. 17, p. 457-478.

-1941, Inter-correlation between growth rates of conifers in northern New England: Tree-Ring Bulletin, v. 7, p 24-36.

-1943, Water supply and growth rates of conifers around Boston: Ecology, v. 24, p. 329-344.

Meyer, H. A., 1941, Growth fluctuations of virgin hemlock from northern Pennsylvania: Tree-Ring Bulletin, v. 7, p. 20-23.

Morrison, D. F., 1967, Multivariate statistical methods: New York, McGraw-Hill, 338 p.

Oosting, H. J., and Hess, D. W., 1956, Microclimate and a relic stand of Tsuga canadensis: Ecology, v. 37, p. 28-29.

Palmer, W. C., 1965, Meteorological drought: U.S. Department of Commerce, Research Paper no. 45, 58 p.

Phipps, R. L., 1961, Analysis of five years dendrometer data obtained within three deciduous forest communities of Neotoma: Ohio Agriculture Experiment Station Research Circular 105.

Reed, J. C., Jr., 1969, Ancient lavas in Shenandoah National Park near Luray, Virginia: U.S. Geological Survey Bulletin 1265, 43 p.

Schumacher, F. X., and Day, B. B., 1939, The influence of precipitation upon the width of annual rings of certain timer trees: Ecological Monographs, v. 9, p. 387-429.

Segars, C. B., Crawford, L. C., and Harvill, A. M., 1951, The occurrence and distribution of hemlock in Alabama: Ecology, v. 32, p. 149-151.

Stickel, P. W., 1933, Drought injury in hemlock-hardwood stands in Connecticut: Journal of Forestry, v. 31, p. 573-577. 
Stockton, C. W., 1973, A dendroclimatic analysis of the Yellowstone National Park region, Wyoming-Montana: Yellowstone, Wyo., Final report prepared for the National Park Service, U.S. Department of the Interior, $56 \mathrm{p}$.

Stockton, C. W., Meko, D. M., and Mitchell, J. M., Jr., 1978, Tree ring ev1dence of a 22-year rhythm of drought area in Western United States and its relationship to the Hale Solar Cycle: Presented at Working Group VIII, U.S./USSR Agreement of Protection of the Environment, $33 \mathrm{p}$.

Stokes, M. A., and Smiley, T. L., 1968, An introduction to tree-ring dating: Chicago, Ill, Chicago Press, 73 p.

Thornthwaite, C. W., 1948, An approach toward a rational classification of climate: Geographical Review, v. 38, p. 55-94. 